\title{
An assessment of geographical distribution of different plant functional types over North America simulated using the CLASS-CTEM modelling framework
}

\author{
Rudra K. Shrestha ${ }^{1}$, Vivek K. Arora ${ }^{1}$, Joe R. Melton ${ }^{2}$, and Laxmi Sushama ${ }^{3}$ \\ ${ }^{1}$ Canadian Centre for Climate Modelling and Analysis, Environment and Climate Change Canada, University of Victoria, \\ Victoria, BC, V8W 2Y2, Canada \\ ${ }^{2}$ Climate Research Division, Environment and Climate Change Canada, Toronto, Ontario, Canada \\ ${ }^{3}$ Département des sciences de la Terre et de l'atmosphère, Université du Québec à Montréal, Quebec, Canada
}

Correspondence to: Vivek K. Arora (vivek.arora@canada.ca)

Received: 4 February 2017 - Discussion started: 6 March 2017

Revised: 20 July 2017 - Accepted: 29 August 2017 - Published: 25 October 2017

\begin{abstract}
The performance of the competition module of the CLASS-CTEM (Canadian Land Surface Scheme and Canadian Terrestrial Ecosystem Model) modelling framework is assessed at $1^{\circ}$ spatial resolution over North America by comparing the simulated geographical distribution of its plant functional types (PFTs) with two observation-based estimates. The model successfully reproduces the broad geographical distribution of trees, grasses and bare ground although limitations remain. In particular, compared to the two observation-based estimates, the simulated fractional vegetation coverage is lower in the arid southwest North American region and higher in the Arctic region. The lower-thanobserved simulated vegetation coverage in the southwest region is attributed to lack of representation of shrubs in the model and plausible errors in the observation-based data sets. The observation-based data indicate vegetation fractional coverage of more than $60 \%$ in this arid region, despite only $200-300 \mathrm{~mm}$ of precipitation that the region receives annually, and observation-based leaf area index (LAI) values in the region are lower than one. The higher-than-observed vegetation fractional coverage in the Arctic is likely due to the lack of representation of moss and lichen PFTs and also likely because of inadequate representation of permafrost in the model as a result of which the $\mathrm{C}_{3}$ grass PFT performs overly well in the region. The model generally reproduces the broad spatial distribution and the total area covered by the two primary tree PFTs (needleleaf evergreen trees, NDLEVG; and broadleaf cold deciduous trees, BDL-DCD-CLD) reasonably well. The simulated fractional coverage of tree
\end{abstract}

PFTs increases after the 1960 s in response to the $\mathrm{CO}_{2}$ fertilization effect and climate warming. Differences between observed and simulated PFT coverages highlight model limitations and suggest that the inclusion of shrubs, and moss and lichen PFTs, and an adequate representation of permafrost will help improve model performance.

\section{Introduction}

The terrestrial ecosystem plays an important role in regulating climate and weather through land-atmosphere exchange of water and energy (Cramer et al., 2001; Garnaud et al., 2015; Pielke et al., 1998; Ran et al., 2016) and in mitigating climate change by sequestering atmospheric $\mathrm{CO}_{2}$ (Bonan, 2008; Timmons et al., 2016). The projected sink of atmospheric $\mathrm{CO}_{2}$ is uncertain due to disagreements among the Earth system models (Arora et al., 2013; Friedlingstein et al., 2006) primarily due to differing responses of their terrestrial ecosystem modules to future changes in atmospheric $\mathrm{CO}_{2}$. This uncertainty arises primarily because of the differences in the strength of the $\mathrm{CO}_{2}$ fertilization effect on the land carbon cycle components (Arora et al., 2013; Cramer et al., 2001; Friend et al., 2013) but also because of differences in the response of vegetation. Models differ in how the spatial distribution of vegetation, and its composition, changes in response to changing climate and increasing $\mathrm{CO}_{2}$ (Cramer et al., 2001). These differences are also resolution dependent. 
For example, models with coarse grid resolutions cannot explicitly resolve climatic niches, which in turn potentially contributes to biases in simulated vegetation distribution (Melton and Arora, 2016; Shrestha et al., 2016).

Vegetation responds to changes in climate and atmospheric $\mathrm{CO}_{2}$ concentration by changing its structural attributes including leaf area index (LAI), rooting depth, vegetation height, and canopy mass, as well as its areal extent. Structural vegetation changes generally occur over seasonal to decadal timescales (Kramer and Kozlowski, 1979), while the slower areal extent changes typically occur on decadal to centennial timescales (Ritchie and Macdonald, 1986). The dynamic behaviour of vegetation affects weather and climate due to its strong control over biophysical processes. At hourly to daily timescales, vegetation affects the exchange of water and energy between the land surface and the atmosphere primarily through the control of leaf stomata. At longer seasonal, annual and decadal timescales, vegetation affects components of energy and water balance through its structure (LAI, rooting depth, etc.) and its areal extent and albedo of the land surface. Conversely, the dynamics of vegetation are directly influenced by climate and the competitive ability of the plants. In this way vegetation responds to climate by changing its structure and areal extent depending on the colonization ability of plants. These climate-vegetation interactions have been well documented (e.g. Gobron et al., 2010; Wang et al., 2011).

Natural vegetation is typically characterized in dynamic global vegetation models (DGVMs) based on a limited number of plant functional types (PFTs; Sitch et al., 2003) because it is impossible to represent thousands of species in a model. Species characterized by similar attributes, mainly based on their form and interactions with the environment (Box, 1996), are grouped together as a single PFT. For example, tree species with similar leaf form such as fir (Abies), spruce (Picea) and pine (Pinus) are classified as needleleaf evergreen (NDL-EVG) trees. The geographical distribution of the PFTs in DGVMs is determined by their ability to grow and increase their areal extent given certain climate and soil conditions and their competitive ability.

One way of representing competition between PFTs in DGVMs is through the use of the Lotka-Volterra (LV) equations. While originally developed for predator-prey competition, the LV equations have been used in a number of DGVMs (Arora and Boer, 2006; Brentnall et al., 2005; Cox, 2001; Zhang et al., 2015). The use of the classical form of the LV equations for modelling competition between PFTs, however, leads to an amplified expression of dominance in that the dominant PFT ends up occupying a disproportionately large fraction of a grid cell, leading to little coexistence between PFTs. Arora and Boer (2006) proposed changes to the classical implementation of the LV equations for modelling competition between PFTs to reduce this amplified expression of dominance. Their approach, which has been implemented in the CLASS-CTEM (Canadian
Land Surface Scheme and Canadian Terrestrial Ecosystem Model) modelling framework and which allows improved co-existence of PFTs compared to the classical LV equations, has been shown to simulate vegetation distribution reasonably well at the global (Melton and Arora, 2016) as well as point (Shrestha et al., 2016) scales. Both these studies used climate averaged over $\sim 3.75^{\circ}$ spatial resolution. The CLASS-CTEM framework consists of the Canadian Land Surface Scheme (CLASS) coupled to the Canadian Terrestrial Ecosystem Model (CTEM), which is a dynamic vegetation model.

In this paper, we evaluate the competition module of the CLASS-CTEM modelling framework at the regional scale over the North American domain at $1^{\circ}$ spatial resolution. This resolution is much finer than the $3.75^{\circ}$ resolution used in the Melton and Arora (2016) study and therefore in principle should allow a more realistic simulation of the geographical distribution of PFTs as climate niches are resolved.

The rest of this paper is organized as follows: Sect. 2 describes the CLASS-CTEM modelling framework, details of the observation-based data and the experimental setup. Results are presented in Sect. 3, and a discussion follows in Sect. 4. Finally, a summary and conclusions are provided in Sect. 5 .

\section{Model, data and methods}

\subsection{CLASS-CTEM model}

The results presented here are obtained by coupling version 2.0 of CTEM (Melton and Arora, 2016), which dynamically simulates fractional coverage of its PFTs, to version 3.6 of CLASS (Verseghy et al., 1993). CTEM simulates terrestrial processes for seven non-crop and two crop PFTs (Table 1) and prognostically tracks carbon in three living vegetation components (leaves, stems and roots) and two dead carbon pools (litter and soil). The terrestrial ecosystem processes simulated in this study include photosynthesis, autotrophic respiration, heterotrophic respiration, dynamic leaf phenology, allocation of carbon from leaves to stem and root components, fire, land use change and competition between PFTs which dynamically determines the fractional coverage of each PFT. The amount of carbon in the leaf, stem and root components is used to estimate structural attributes of vegetation. LAI is calculated from leaf biomass using PFT-dependent specific leaf area, which determines the area of leaves that can be constructed per $\mathrm{kgC}$ of leaf biomass (Arora and Boer, 2005); vegetation height is calculated based on stem biomass for tree PFTs and LAI for grass PFTs; and rooting depth is calculated based on root biomass (Arora and Boer, 2003). CTEM operates at a time step of 1 day except for photosynthesis and leaf respiration, which are calculated every 30 min for consistency with CLASS' energy and water 
Table 1. Plant functional types (PFTs) represented in CTEM and their relation to CLASS PFTs.

\begin{tabular}{lll}
\hline CLASS PFTs & CTEM PFTs & CTEM PFT symbol \\
\hline \multirow{2}{*}{ Needleleaf trees } & Needleleaf evergreen trees & NDL-EVG \\
& Needleleaf deciduous trees & NDL-DCD \\
Broadleaf trees & Broadleaf evergreen trees & BDL-EVG \\
& Broadleaf cold deciduous trees & BDL-DCD-CLD \\
& Broadleaf drought/dry deciduous trees & BDL-DCD-DRY \\
Crops & $\mathrm{C}_{3}$ crops & CROP-C3 \\
& $\mathrm{C}_{4}$ crops & CROP-C4 \\
Grasses & $\mathrm{C}_{3}$ grasses & GRASS-C3 \\
& $\mathrm{C}_{4}$ grasses & GRASS-C4 \\
\hline
\end{tabular}

balance calculations which require stomatal resistance calculated by the photosynthesis module of CTEM.

CLASS simulates the energy and water balance components at the land surface and operates at a 30 min time step. Liquid and frozen soil moisture and soil temperature are evaluated for three soil layers (with maximum thicknesses of 0.1 , 0.25 and $3.75 \mathrm{~m}$ ). The actual thicknesses of these permeable soil layers are determined by the depth to bedrock, which is specified on the basis of the global data set of Zobler (1986). CLASS distinguishes four PFTs (needleleaf trees, broadleaf trees, crops and grasses) which map directly to the nine PFTs represented in CTEM as shown in Table 1. Needleleaf trees in CTEM are divided into deciduous and evergreen types, broadleaf trees are divided into cold and drought deciduous and evergreen types, and crops and grasses are divided into $\mathrm{C}_{3}$ and $\mathrm{C}_{4}$ types based on their photosynthetic pathways. In coupled mode, CLASS uses the dynamically simulated vegetation attributes (including LAI, vegetation height, canopy mass and rooting depth) and stomatal resistance calculated by CTEM, and CTEM uses the soil moisture, soil temperature and net shortwave radiation calculated by CLASS. The coupling frequency between CLASS and CTEM is 1 day.

\subsubsection{Competition parameterization}

Competition between PFTs in CTEM is parameterized following Arora and Boer (2006), who presented a modified version of the LV equations. The approach is described in detail by Melton and Arora (2016) and briefly summarized here. Consider, for simplicity, two PFTs that exist in a grid cell with fractional coverages $f_{1}$ and $f_{2}$. Let PFT 1 represent a tree PFT and PFT 2 represent a grass PFT. The bare fraction of grid cell not covered by any vegetation is represented by $f_{\mathrm{B}}$. As a result, $f_{1}+f_{2}+f_{\mathrm{B}}=1$. The rate of change of fractional coverages of the two PFTs and bare fraction, for this example, are given by

$$
\begin{aligned}
& \frac{\mathrm{d} f_{1}}{\mathrm{~d} t}=c_{1} f_{1}^{\beta}\left(1-f_{1}\right)-m_{1} f_{1}, \\
& \frac{\mathrm{d} f_{2}}{\mathrm{~d} t}=c_{2} f_{2}^{\beta}\left(1-f_{1}-f_{2}\right)-c_{1} f_{1}^{\beta} f_{2}-m_{2} f_{2},
\end{aligned}
$$

$\frac{\mathrm{d} f_{\mathrm{B}}}{\mathrm{d} t}=-c_{1} f_{1}^{\beta} f_{\mathrm{B}}-c_{2} f_{2}^{\beta} f_{\mathrm{B}}+m_{1} f_{1}+m_{2} f_{2}$,

where $c_{1}, c_{2}$ and $m_{1}, m_{2}$ are the colonization and mortality rates for PFT 1 and PFT 2, respectively. Colonization and mortality rates cannot be negative. Equations (1) and (2) show that PFT 1 can invade the fraction covered by PFT 2 and the bare fraction and that PFT 2 can only invade the bare fraction. PFT 2 is not allowed to invade the fraction covered by PFT 1 because it is ranked lower than PFT 1. In CTEM, the superiority or ranking of the seven natural non-crop PFTs is based on the tree-grass distinction and their colonization rates. Trees are always considered to be superior to grasses because of their ability to shade them (Siemann and Rogers, 2003). Within the tree and grass PFTs the dominance is determined dynamically based on the colonization rate. The exponent $\beta(0 \leq \beta \leq 1)$, an empirical parameter, controls the behaviour of the LV equations. For $\beta=1$, the equations represent the classical form of the LV equations. The equilibrium fractional coverages for PFT 1 and 2 and bare fraction for this classical form of the LV equations, denoted by $\widetilde{f}_{1}$, $\widetilde{f}_{2}$, and $\widetilde{f}_{\mathrm{B}}$, are given by

$\tilde{f}_{1}=\max \left\{\left(\frac{c_{1}-m_{1}}{c_{1}}\right), 0\right\}$,
$\tilde{f}_{2}=\max \left\{\left(\frac{\left(c_{2}-m_{2}\right)-\left(1+\frac{c_{2}}{c_{1}}\right)\left(c_{1}-m_{1}\right)}{c_{2}}\right), 0\right\}$,

$\widetilde{f_{\mathrm{B}}}=\frac{\left(m_{1} \widetilde{f}_{1}+m_{2} \widetilde{f}_{2}\right)}{\left(c_{1} \widetilde{f_{1}}+c_{2} \widetilde{f}_{2}\right)}$

In Eqs. (1) and (2), if the fractional coverages of PFT 1 and PFT 2 are initially zero then the PFTs cannot expand for $\beta=1$, implying that a minimum seeding fraction is always required. Furthermore, in Eq. (5) as long as $\left(c_{1}-m_{1}\right)$ is greater than $\left(c_{2}-m_{2}\right)$ then the equilibrium solution for $f_{2}$ will always be zero and PFT 2 will not be able to coexist with PFT 1. These features of the classical form of the LV equations are avoided when $\beta=0$, following Arora and Boer (2006). The equilibrium fractional coverages for PFT 1 and 
(a) Mean annual precipitation

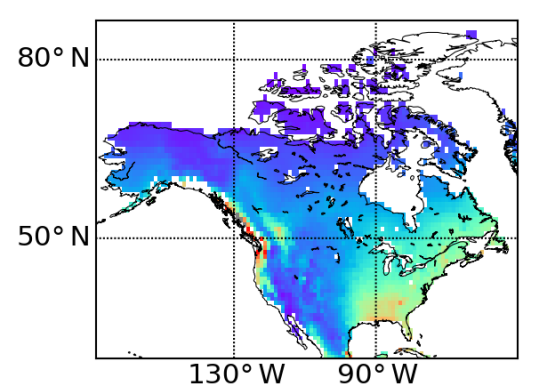

(b) Mean annual temperature

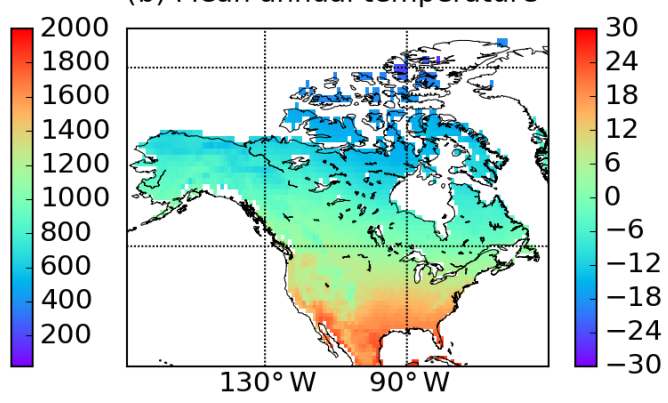

Figure 1. Spatial distribution of mean annual (a) precipitation $(\mathrm{mm})$ and (b) temperature $\left({ }^{\circ} \mathrm{C}\right)$ across North America. Grid cells with permanent ice/glaciers have been masked out.

2 and bare fraction for the case with $\beta=0$ are given by

$\widetilde{f_{1}}=\left(\frac{c_{1}}{c_{1}+m_{1}}\right)$

$\tilde{f}_{2}=\frac{c_{2}\left(1-\tilde{f}_{1}\right)}{\left(c_{1}+c_{2}+m_{2}\right)}=\left(\frac{c_{2} m_{1}}{\left(c_{1}+m_{1}\right)\left(c_{1}+c_{2}+m_{2}\right)}\right)$,

$\widetilde{f_{\mathrm{B}}}=\frac{\left(m_{1} \widetilde{f}_{1}+m_{2} \widetilde{f}_{2}\right)}{\left(c_{1}+c_{2}\right)}$.

Unlike the classical version of the LV equations, the modified version of the equations with $\beta=0$ does not require a minimum seeding fraction, and PFTs are able to increase their areal extent as long as the climate is favourable and $c_{i}$ is positive. Also, as long as $m_{1}>0$ and $c_{2}>0$ then PFT 2 is able to coexist at equilibrium with PFT 1. Other values of $\beta$ between 0 and 1 give the dominant PFT varying levels of access to subdominant PFTs, but coexistence is most possible in the case with $\beta=0$.

The calculations of colonization and mortality rates are described in detail in Melton and Arora (2016). Briefly, the colonization rate depends on the net primary productivity (NPP) of a PFT. The better a PFT performs for given climatic and soil conditions, the higher is its colonization rate. The mortality rate represents the combined effect of four different processes: intrinsic or age-related mortality, growth or stress mortality, mortality due to disturbance and mortality due to adverse climate which ensures that tree PFTs do not venture outside their bioclimatic zones.

\subsection{Forcing data}

The Climate Research Unit-National Centers for Environmental Prediction (CRU-NCEP) reanalysis data set (Viovy, 2012) is used to drive the model. The meteorological variables (surface temperature, pressure, precipitation, wind, specific humidity, and incident shortwave and long-wave radiation fluxes) are available at a spatial resolution of $0.5^{\circ} \times$ $0.5^{\circ}$ and at a 6-hourly time interval for the period 19012010. These data are interpolated to $1^{\circ}$ resolution spatially and disaggregated to half-hourly time resolution, a standard CLASS-CTEM model integration time step. Temperature, pressure, wind, specific humidity and long-wave radiation are linearly interpolated in time while shortwave radiation is assumed to change with the solar zenith angle with maximum radiation occurring at solar noon. Following Arora (1997), the 6-hourly precipitation amount $(P, \mathrm{~mm} / 6 \mathrm{~h})$ is used to estimate the number of wet half-hours $\left(w_{\mathrm{h}}\right)$ in a given $6 \mathrm{~h}$ period for $P>0$ as

$w_{\mathrm{h}}=\operatorname{integer}(\max [1, \min (12,2.6 \log (6.93 P))])$.

The total precipitation amount is then distributed randomly but conservatively over these wet half-hours. For instance, if 7 out of 12 half-hour intervals are calculated to be wet using Eq. (10) then seven random numbers varying between 0 and 1 are generated and the 6-hourly precipitation amount is divided into seven parts in proportion to their respective random numbers.

Figure 1 shows the spatial distribution of mean annual precipitation and surface temperature over the North American domain considered in this study. Mean annual precipitation values range from less than $200 \mathrm{~mm}$ in the arid southwest US and the high Arctic to more than $1500 \mathrm{~mm}$ on the Pacific coast. Mean annual temperature varies from around $24^{\circ} \mathrm{C}$ near the southern limit of the domain in Mexico to less than $-20^{\circ} \mathrm{C}$ in the Arctic tundra.

\subsection{Observation-based data}

\subsubsection{Fractional coverage of PFTs}

Observation-based estimates of fractional coverages of PFTs are based on a modified version of the Wang et al. (2006) data set (hereafter WANG06) and the Moderate Resolution Imaging Spectroradiometer land cover product (hereafter MODIS; Friedl et al., 2013). These data are used to evaluate the model results. 
Table 2. Reclassification of the 17 MODIS land cover classes into the nine CTEM PFTs.

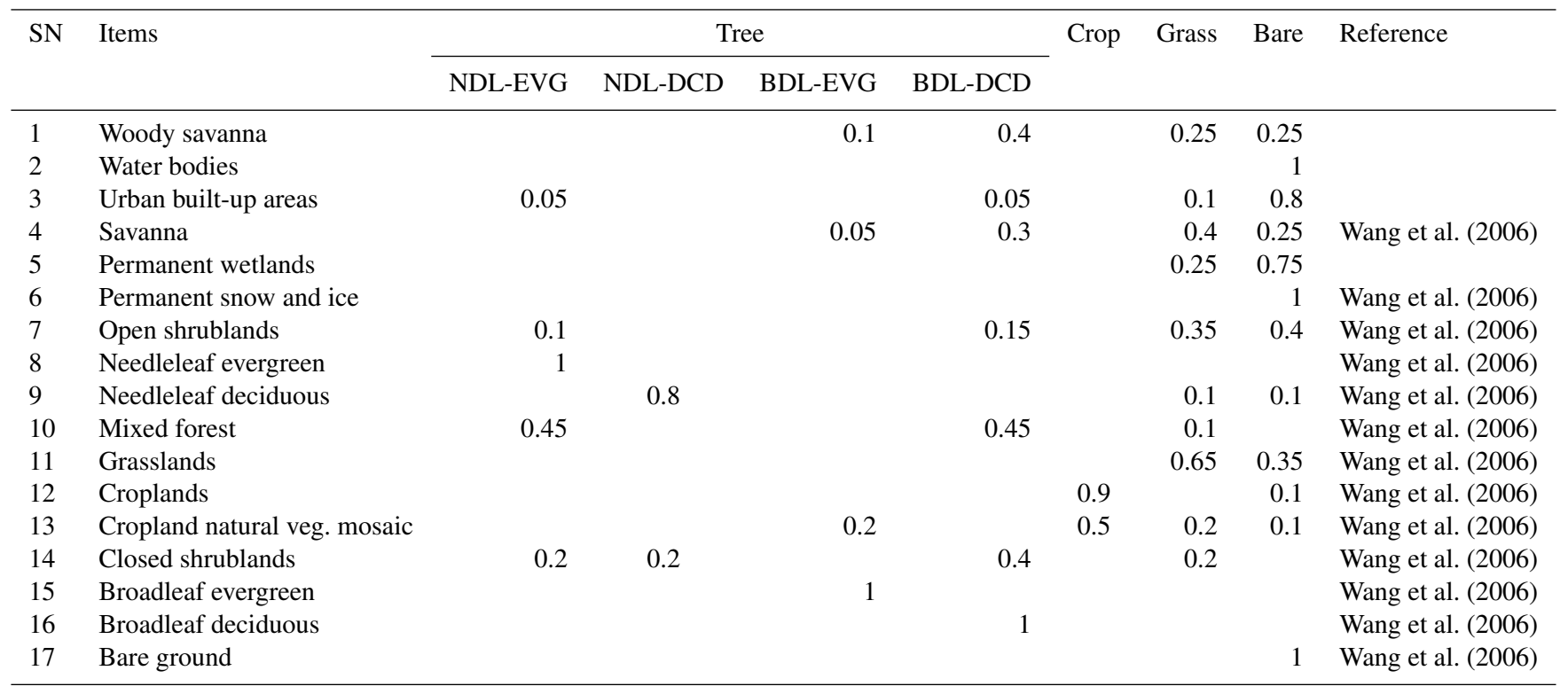

The WANG06 data set was developed for use by CTEM in simulations in which competition is turned off and prescribed fractional coverage of PFTs is used. It combines observationand model-based data to estimate the annual change in fractional coverage of CTEM's nine PFTs from 1850 to 2000. The global land cover data set for the year 2000 (GLC2000), which is considered as a base year for environmental assessment, divides the global land cover into 22 types and is available at $1 \mathrm{~km}$ resolution. WANG06 (their Table 2) mapped the GLC2000 data to CTEM's nine PFTs aggregated to $0.5^{\circ}$ resolution. The GLC2000 data were then extrapolated back to 1850 by adjusting the changes in crop area based on the then available Ramankutty and Foley (1999) crop data set. Here, we use a modified version of the WANG06 data set which is based on the HYDE version 3.1 crop data set (Hurtt et al., 2011) and generate an estimate of fractional coverage of CTEM PFTs for the period 1850-2012.

The MODIS data set is based on the International Geosphere-Biosphere Programme (IGBP) global vegetation data and University of Maryland's science data set classification schemes at $0.25^{\circ}$ spatial resolution. The data are derived from the NASA HDF-EOS MODIS/Terra land cover type data set. The data set is for the period 2001 to 2014 and contains 17 land cover types which we map to CTEM's nine PFTs following the logic used in Wang et al. (2006) as shown in Table 2. The fractional coverage of each of the nine CTEM PFTs is first obtained at $0.25^{\circ}$ resolution for each year using the mapping scheme described in Table 2. These fractional coverages are then re-gridded to the $1^{\circ}$ spatial resolution for individual years. Finally, the data are averaged over the period 2001-2014 to evaluate model results. MODIS data are known to exhibit substantial interannual variability. Broxton et al. (2014), for instance, report that globally $40 \%$ of land pixels show land cover change one or more times during the 2001-2010 period. This does not necessarily indicate changes in land cover but rather these differences are due to low accuracy in categorizing the remotely sensed vegetation into one of the 17 MODIS land cover types, as Broxton et al. (2014) note. This low accuracy is itself attributed to the fact that many landscapes include mixtures of vegetation classes. Our re-gridding of fractional coverages to $1^{\circ}$ spatial resolution and averaging over the 2001-2014 time period to obtain climatology of land cover alleviates some of the uncertainty since the effect of inaccurately classified land cover categories is reduced due to both spatial and temporal averaging.

The separation of the broadleaf deciduous PFT into its drought and cold deciduous components is performed via the approach used by WANG06. They assumed that below $24^{\circ} \mathrm{N}$ deciduousness is caused by soil moisture limitation and hence all broadleaf deciduous trees below this latitude are drought deciduous, and above $34^{\circ} \mathrm{N}$ deciduousness is caused by low temperatures and so all broadleaf deciduous trees above this latitude are cold deciduous. Between $24^{\circ} \mathrm{N}$ and $34^{\circ} \mathrm{N}$, following WANG06, we assume a linear transition from drought deciduous to cold deciduous trees. Finally, the separation of grasses into their $\mathrm{C}_{3}$ and $\mathrm{C}_{4}$ components is based on the geographical distributions of the $C_{3}$ and $C_{4}$ fractions in the WANG06 data set.

\subsubsection{Gross primary productivity and LAI}

Observation-based estimates of gross primary productivity (GPP) are based on Beer et al. (2010). These data are based on the ecosystem-level GPP obtained using eddy covariance measurements from more than 250 stations across the globe. 
Beer et al. (2010) extrapolated GPP values based on these eddy covariance flux data to the global scale using diagnostic models for the period 1982-2008, and the average over this time period is used to evaluate the model results. LAI data used for validation are the same as those used by Anav et al. (2013) and are based on Zhu et al. (2013), who use normalized difference vegetation index (NDVI) data from the Advanced Very High Resolution Radiometer (AVHRR) satellite to calculate average LAI for the period 1981-2010.

\subsection{Experimental setup}

\subsubsection{Equilibrium pre-industrial simulation}

The equilibrium pre-industrial simulation was initialized from zero biomass and zero fractional coverage for all noncrop PFTs. The fractions of $\mathrm{C}_{3}$ and $\mathrm{C}_{4}$ crop PFTs in each grid cell are specified corresponding to year 1850 based on the HYDE 3.1 data set. The model was then run for 600 years driven by 1901-1925 CRU-NCEP climate data cycled repeatedly. These data do not show any warming trend (Wen et al., 2011) as opposed to the later part of the 20th century. Atmospheric $\mathrm{CO}_{2}$ concentration was set to $285 \mathrm{ppm}$, corresponding to the pre-industrial 1850 level. This preindustrial equilibrium simulation yields initial conditions including fractional coverages of PFTs and carbon in all the live and dead pools for the transient 1850-2010 simulation. The 600-year simulation is sufficient for fractional vegetation cover and carbon pools to reach equilibrium.

\subsubsection{Transient historical simulation}

The transient historical simulation is performed for the period 1851-2010, and its carbon pools and fractional coverage of non-crop PFTs are initialized from the equilibrium pre-industrial simulation as mentioned above. The years 1851 to 1900 of this historical simulation are driven with CRU-NCEP climate data corresponding to the period 19011925, cycled twice. For the period 1901-2010 the climate data corresponding to each year are used. Time-varying concentrations of atmospheric $\mathrm{CO}_{2}$ are supplied for the period 1851-2010 based on the values used in the fifth Coupled Model Intercomparison Project (CMIP5, https://tntcat.iiasa. ac.at/RcpDb/), which are extended past 2005 to 2010 based on data from the National Oceanic and Atmospheric Administration (ftp://aftp.cmdl.noaa.gov/products/trends/co2/co2_ annmean_gl.txt). The annual time-varying fractional coverages of $\mathrm{C}_{3}$ and $\mathrm{C}_{4}$ crop PFTs in each grid cell are based on the HYDE 3.1 data set. The crop fractions in a grid cell are not available for colonization and neither are they subject to disturbance by fire. Competition between PFTs occurs over the remaining non-crop fraction of a grid cell. As the total crop fraction in a grid cell changes over time (based on the HYDE 3.1 data set), the fractional area available for competition also changes.
The simulated results are evaluated against their observation-based counterparts using averaged values over the last 30 years of the simulation corresponding to the period 1981-2010. This is the same and/or very close to the time period for the modified WANG06 land cover data set (1981-2010), Beer et al. (2010) GPP (1982-2008) and Zhu et al. (2013) LAI (1981-2010). The only exception is the MODIS-based land cover data which are available for the 2001-2014 period.

\section{Results}

\subsection{Continental-scale values of PFT coverage}

Figure 2a compares the simulated vegetation areas summed over our North American domain with the WANG06 and MODIS observation-based estimates. In the absence of another measure of uncertainty, we use the range between these two observation-based estimates and assess whether simulated areal coverage of a given land cover type lies within or outside this range. The simulated total vegetated area over North America $\left(14.8 \times 10^{6} \mathrm{~km}^{2}\right)$ is very similar to the modified WANG06- $\left(14.4 \times 10^{6} \mathrm{~km}^{2}\right)$ and MODISbased $\left(14.2 \times 10^{6} \mathrm{~km}^{2}\right)$ estimates. At the most basic treegrass-bare ground level, the simulated areas are closer to the MODIS-based estimates than to the estimate based on the modified WANG06 data. The simulated area covered by tree PFTs $\left(7.8 \times 10^{6} \mathrm{~km}^{2}\right)$ is $6 \%$ lower than the MODIS-derived estimate $\left(8.2 \times 10^{6} \mathrm{~km}^{2}\right)$ and $21 \%$ lower than WANG06 $\left(9.7 \times 10^{6} \mathrm{~km}^{2}\right)$. The simulated grass coverage $\left(4.7 \times 10^{6} \mathrm{~km}^{2}\right)$ is $35 \%$ higher than the MODIS-derived estimate $\left(3.5 \times 10^{6} \mathrm{~km}^{2}\right)$. Both simulated and MODIS-based estimates of area covered by grass PFTs are, however, substantially higher than the WANG06 $\left(2.4 \times 10^{6} \mathrm{~km}^{2}\right)$ estimate. Averaged over the North American region, the simulated partitioning of land area (excluding cropland area) covered by trees, grasses and bare ground (45, 27 and $28 \%$ ) is much closer to the MODIS-based data $(48,20$ and $32 \%)$ than to the modified WANG06-based data (56, 14 and $30 \%)$.

Figure $2 b$ shows a comparison of simulated areas of individual PFTs with observation-based estimates. This is a more stringent test of the performance of the competition module of CTEM. The observation-based estimates of areas of all individual PFTs are available for the modified WANG06 data set. The MODIS-based estimates were derived based on the mapping of MODIS' 17 land cover types to CTEM PFTs as shown in Table 2, which itself is mostly based on WANG06. In Fig. 2b, the observation-based estimates show that needleleaf evergreen and broadleaf cold deciduous (BDL-DCDCLD) are the dominant tree PFTs across North America and the model is able to reproduce this aspect. The simulated total area of the NDL-EVG tree PFT $\left(3.9 \times 10^{6} \mathrm{~km}^{2}\right)$ is $28 \%$ lower than WANG06 $\left(5.3 \times 10^{6} \mathrm{~km}^{2}\right)$ and $15 \%$ lower than the MODIS-based estimate $\left(4.7 \times 10^{6} \mathrm{~km}^{2}\right)$. The simu- 
(a) Basic tree-grass-bare ground area

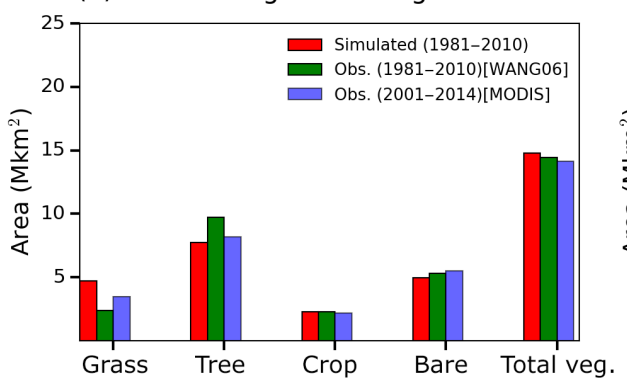

(c) Evolution of tree-grass-bare ground area

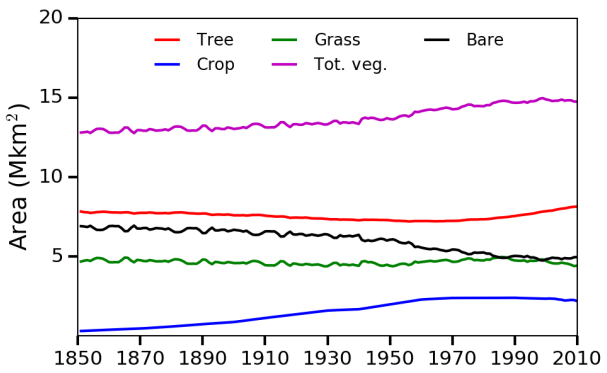

(b) Individual PFTs area

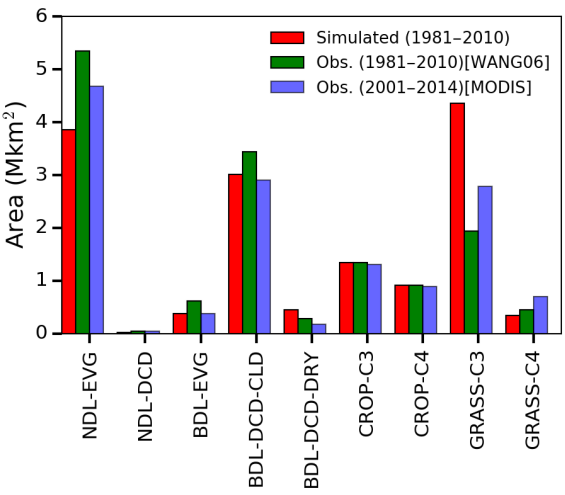

Figure 2. Comparison of observation-based and simulated vegetation areas summed over the North American domain: (a) grass, tree, crop, bare ground and total vegetated area; (b) individual PFT areas; and (c) evolution of simulated vegetation areas summed over the domain.

lated total area of BDL-DCD-CLD tree PFT $\left(3 \times 10^{6} \mathrm{~km}^{2}\right)$ is $13 \%$ lower than WANG06 $\left(3.4 \times 10^{6} \mathrm{~km}^{2}\right)$ and $3 \%$ greater than the MODIS-based $\left(2.9 \times 10^{6} \mathrm{~km}^{2}\right)$ estimate. Overall, the model is able to capture the areas covered by individual PFTs reasonably well. However, differences remain between observations-based and simulated estimates, especially the larger simulated area for $\mathrm{C}_{3}$ grasses than for both observation-based estimates. Reasons for these differences include limitations in the model but also the manner in which remotely sensed vegetation is categorized into broad-scale vegetation types and then mapped onto CTEM's nine PFTs, as discussed later.

In both Fig. 2a and b, although simulated areal coverages at the basic tree-grass-bare ground level and for individual PFTs (except for $\mathrm{C}_{3}$ grasses) are comparable to observationbased estimates, they are outside the range defined by difference of the WANG06 and MODIS-based estimates.

Figure $2 \mathrm{c}$ shows the time series of simulated areas summed over the domain covered by tree and grass PFTs, the total vegetated area and the remaining bare ground. The specified area covered by crop PFTs, based on the HYDE 3.1 data set, is also shown and first increases over the historical period and then stabilizes, and in fact somewhat decreases, in association with cropland abandonment over the northeastern US. The increase in the crop area results in a decrease in the area covered by tree and grass PFTs up until the time when the crop area stabilizes around 1970. In the model, this causes land use change emissions associated with deforestation. After this time, as vegetation productivity responds to increas- ing atmospheric $\mathrm{CO}_{2}$ concentration, the area covered by tree PFTs increases somewhat and colonizes available bare areas and those covered by grass PFTs. This leads to a small reduction in the area covered by grass PFTs as well as bare ground and the associated increase in the total vegetated area.

\subsection{Geographical distribution of PFTs}

\subsubsection{Total vegetated and bare ground fractions}

Figures 3 and 4 compare the geographical distribution of simulated total vegetated and bare fractions across North America with the two observation-based estimates derived from the modified WANG06 and MODIS data sets. The two observation-based estimates are also compared amongst themselves. The metrics used are the averaged root mean square difference (RMSD) and spatial correlations $\left(R^{2}\right)$.

The observation-based geographical distribution of vegetated fraction in Fig. 3 (middle column) shows densely vegetated land over the eastern part of the continent and less vegetation coverage over colder regions in the north and drier regions in the south-central and southwest US. These broadscale patterns are consistent with the precipitation and temperature climatologies of the region (Fig. 1). The model reasonably reproduces the observed vegetation distribution (left panel) with some obvious limitations. Simulated vegetation cover is underestimated across the arid southwest US, Great Plains and part of the Canadian Prairies (right panel) due to lower simulated fractional coverage of tree and grass PFTs 


\section{Total vegetated fraction}

(a) Simulated (1981-2010)

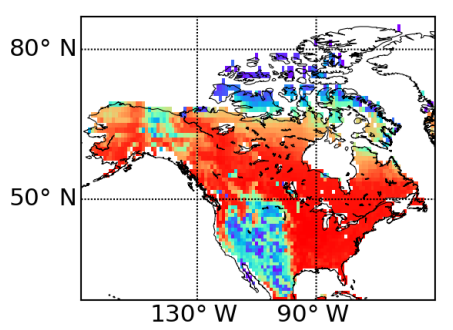

(b) Obs. (1981-2010) [WANG06]
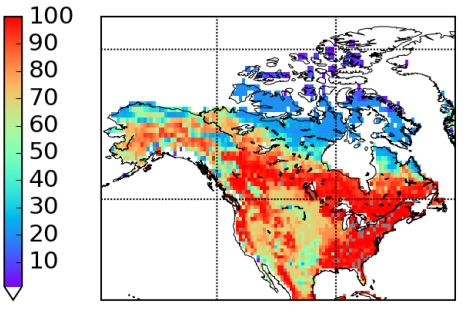

(d) Obs. (2001-2014) [MODIS]

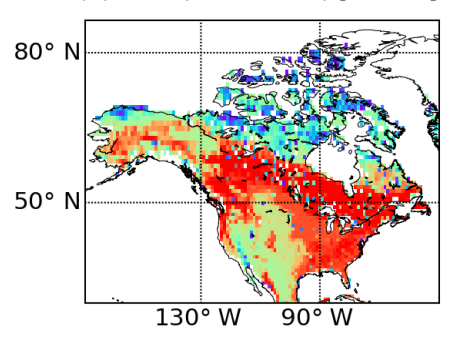

(c) Simulated - WANG06
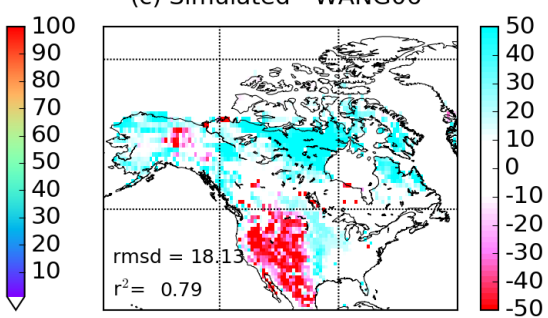

(e) Simulated - MODIS

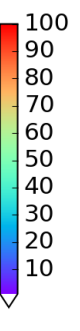

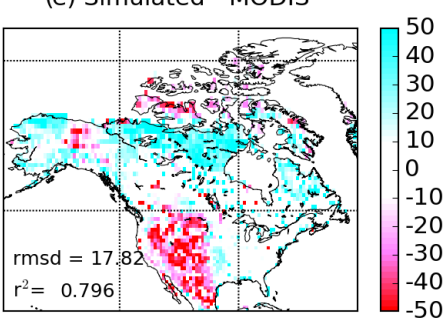

(f) MODIS - WANG06

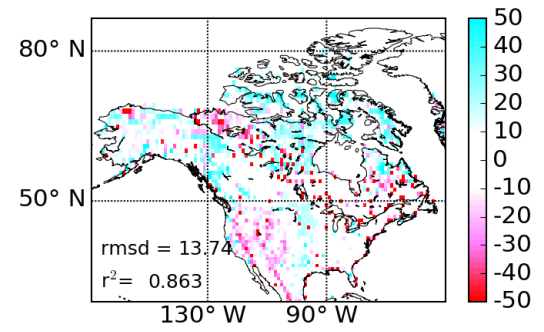

Figure 3. Spatial distribution of total vegetated coverage across North America. Model-simulated results are shown in the left column (a) and the two observation-based estimates are shown in the middle column (b, d). The right column (c, e, f) shows the difference between modeland observation-based estimates (simulated minus WANG06 in c, and simulated minus MODIS in e), and the observation-based estimates themselves (MODIS minus WANG06 in $\mathbf{f}$ ) along with the root mean square difference (rmsd) and spatial correlation $\left(R^{2}\right)$ between the two estimates being compared.

over these regions (shown in Sect. 3.2.2). The model overestimates vegetation coverage in Northern Canada because of higher simulated grass cover in the Arctic as discussed below in more detail. The spatial correlation and RMSD when comparing simulated vegetated fraction to both observationbased estimates are 0.79 and around $18 \%$, respectively. The spatial correlation and RMSD between the two observationbased estimates themselves are 0.86 and around $14 \%$, respectively.

The simulated and observation-based bare ground fractions across North America are compared in Fig. 4. The observation-based estimates show that bare ground fraction is higher in Arctic Canada and Alaska where, of course, cold temperatures limit vegetation growth and in the southwest US, Great Plains and the Prairies where low rainfall limits vegetation growth (Fig. 1). The biases in simulated bare ground fraction mirror those in the simulated vegetated fraction but in an opposite manner. The model underestimates bare ground fraction across Arctic Canada due to higher simulated grass cover as discussed in the next section. The model overestimates the bare ground fraction generally across the arid and semi-arid southwest US, Great Plains and the Prairies. The spatial correlations and RMSDs when comparing simulated bare ground fraction to both observationbased estimates and when comparing the two observationbased data sets amongst themselves are the same as those for the total vegetation fraction in Fig. 3.

\subsubsection{Tree and grass cover}

Figure 5 compares the simulated tree cover with the two observation-based estimates. The model reasonably reproduces the broad-scale patterns including the Canadian boreal forest and the temperate forests across the southeastern US. However, the model simulates lower tree cover across the western part of the continent compared to both observationbased estimates particularly over the southwestern US, which is characterized by arid climate (Fig. 1). The observationbased estimates do not particularly well agree over this re- 
Bare fraction

(a) Simulated (1981-2010)

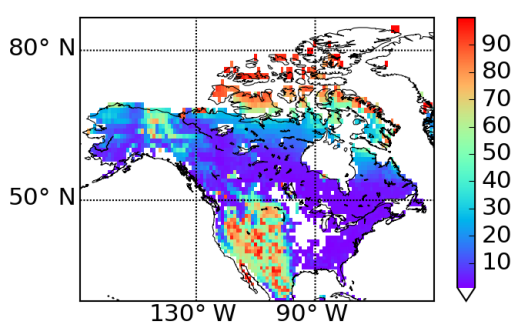

(b) Obs. (1981-2010) [WANG06]

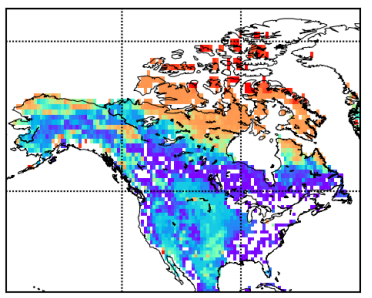

(d) Obs. (2001-2014) [MODIS]

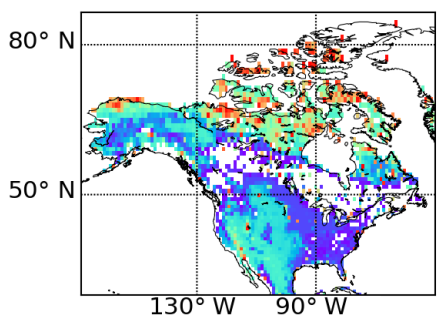

(c) Simulated - WANG06

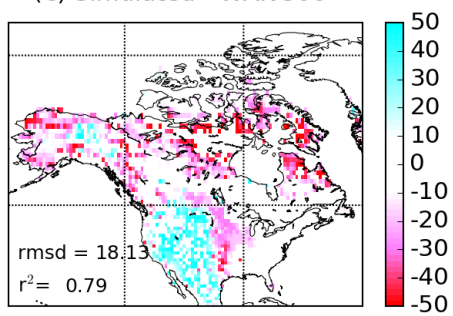

(e) Simulated - MODIS

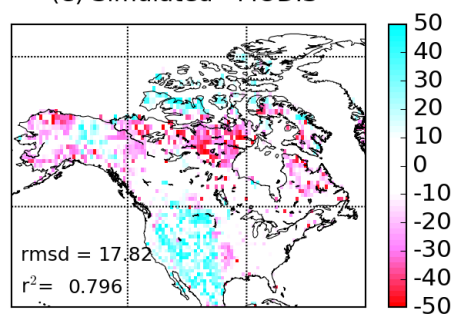

(f) MODIS - WANG06

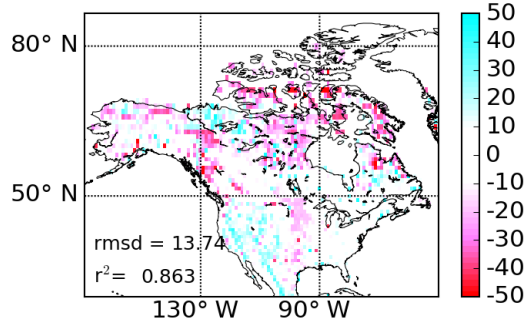

Figure 4. Spatial distribution of bare ground coverage across North America. Model-simulated results are shown in the left column (a) and the two observation-based estimates are shown in the middle column (b, $\mathbf{d})$. The right column (c, e, f) shows the difference between modeland observation-based estimates (simulated minus WANG06 in c, and simulated minus MODIS in e), and the observation-based estimates themselves (MODIS minus WANG06 in $\mathbf{f}$ ) along with the root mean square difference (rmsd) and spatial correlation $\left(R^{2}\right)$ between the two estimates being compared.

gion either. The MODIS-derived estimate suggests around $25 \%$ tree cover in the southwestern US, while the WANG06derived estimate suggests a tree cover of around $60 \%$ over a large area in the region. The spatial correlation and RMSD when comparing simulated tree cover to both observationbased estimates are around 0.68 and around $17 \%$, respectively. The spatial correlation and RMSD between the two observation-based estimates themselves are 0.75 and around $15 \%$, respectively. Possible reasons for differences between simulated and observation-based estimates are discussed in detail in the discussion section and include the fact that the CLASS-CTEM framework does not currently represent shrubs and that there are limitations in the observation-based data sets themselves. Shrubs are more prevalent in arid and semi-arid regions where they are better suited to grow compared to both trees and grasses.

Figure 6 compares the geographical distribution of the simulated grass cover with the two observation-based estimates. The broad geographical distribution of simulated grass cover compares well with the two observation-based estimates, with the notable exception of the Arctic region including Alaska and Northern Canada, where the model overestimates grass cover. This overestimation of grass cover in the Arctic region is also the reason for the overestimation of total vegetation fraction and the underestimation of bare fraction that was seen earlier in Figs. 3 and 4, respectively.

As shown in Fig. 6, the spatial correlation and RMSD when comparing simulated grass cover to both observationbased estimates lie between 0.33 and 0.38 and between around 15 and $17 \%$, respectively. The spatial correlation and RMSD between the two observation-based estimates themselves are 0.54 and around $9 \%$, respectively. The two observation-based estimates disagree most markedly over the western half of the US, where the MODIS-derived estimates of grass cover are higher. 
Tree

(a) Simulated (1981-2010)

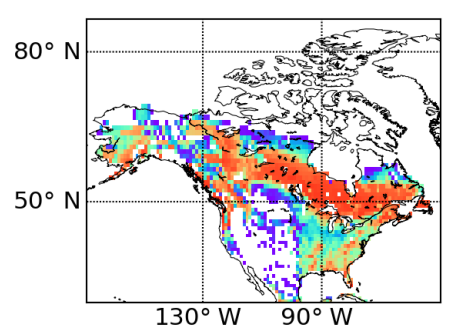

(b) Obs. (1981-2010) [WANG06]

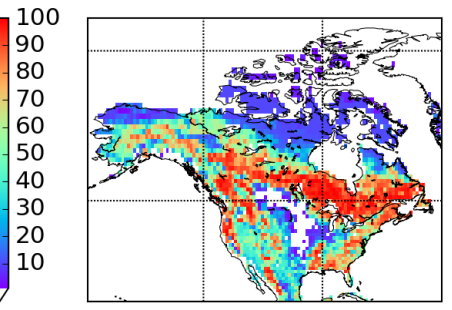

(d) Obs. (2001-2014) [MODIS]

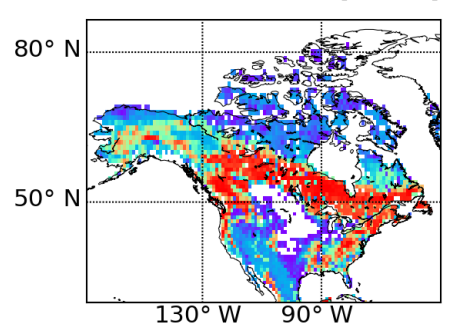

(c) Simulated - WANG06

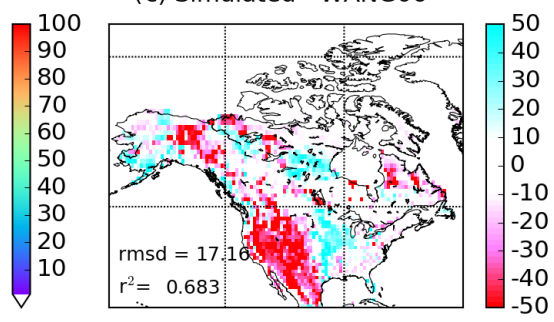

(e) Simulated - MODIS

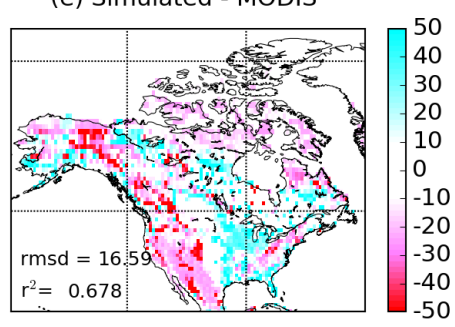

(f) MODIS - WANG06

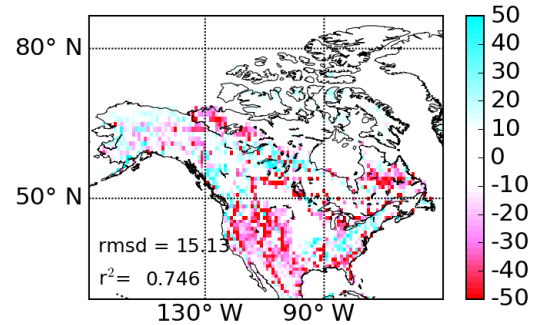

Figure 5. Spatial distribution of tree coverage across North America. Model-simulated results are shown in the left column (a) and the two observation-based estimates are shown in the middle column $(\mathbf{b}, \mathbf{d})$. The right column (c, e, f) shows the difference between modeland observation-based estimates (simulated minus WANG06 in c, and simulated minus MODIS in e), and the observation-based estimates themselves (MODIS minus WANG06 in f) along with the root mean square difference (rmsd) and spatial correlation $\left(R^{2}\right)$ between the two estimates being compared.

\subsubsection{Needleleaf evergreen and broadleaf cold deciduous trees}

Figure $7 \mathrm{a}$ and $\mathrm{b}$ compare the geographical distribution of NDL-EVG and BDL-DCD-CLD trees, respectively, with their observation-based estimates. These two are the primary tree PFTs which exist in the North American domain considered here.

In Fig. 7a, the overall simulated coverage of NDL-EVG trees is lower than both observation-based estimates as was also seen in Fig. 2b. The simulated values are primarily lower in western Canada and over a large area in the western US according to estimates based on the modified WANG06 data set. This is also the case along the wide swath of the Canadian boreal forest. The model overestimates the coverage of NDL-EVG trees in the eastern US. The spatial correlation and RMSD when comparing simulated coverage of NDLEVG trees to both observation-based estimates lie between 0.36 and 0.40 and between around 16 and $17 \%$, respec- tively. The spatial correlation and RMSD between the two observation-based estimates themselves are 0.52 and around $16 \%$, respectively.

The geographical distribution of BDL-DCD-CLD trees is compared with its observation-based estimates in Fig. 7b. Although the simulated domain-summed area of BDL-DCDCLD trees $\left(3 \times 10^{6} \mathrm{~km}^{2}\right)$ is comparable to estimates based on the modified WANG06 $\left(3.4 \times 10^{6} \mathrm{~km}^{2}\right)$ and MODIS $(2.9 \times$ $10^{6} \mathrm{~km}^{2}$ ) data sets, there are two primary limitations in its simulated geographical distribution. First, the simulated values are generally overestimated in Canadian boreal forests and underestimated in the eastern US. Second, the model simulates near-zero coverage in the arid southwestern US. The spatial correlation and RMSD when comparing simulated coverage of BDL-DCD-CLD trees to both observationbased estimates are around 0.3 and around $12 \%$, respectively. The spatial correlation and RMSD between the two observation-based estimates themselves are 0.60 and around $8 \%$, respectively. 
Grass

(a) Simulated (1981-2010)

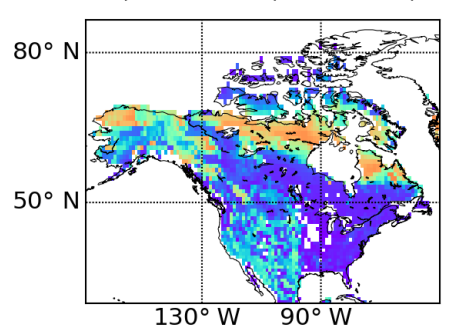

(b) Obs. (1981-2010) [WANG06]
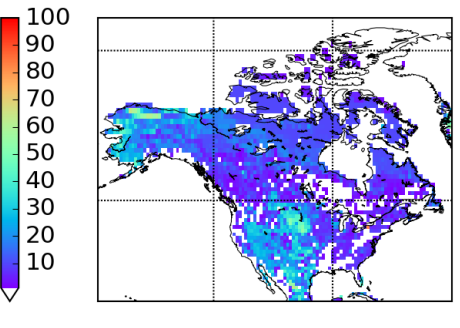

(d) Obs. (2001-2014) [MODIS]

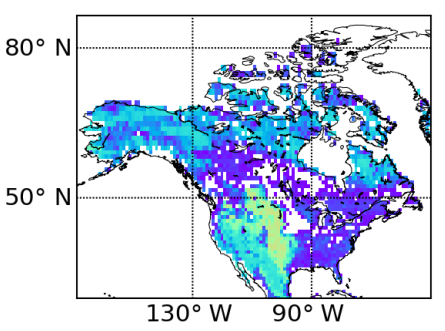

(c) Simulated - WANG06

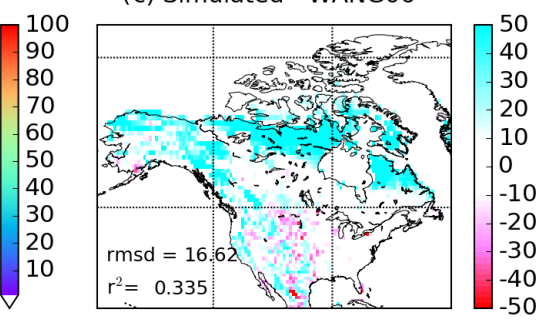

(e) Simulated - MODIS

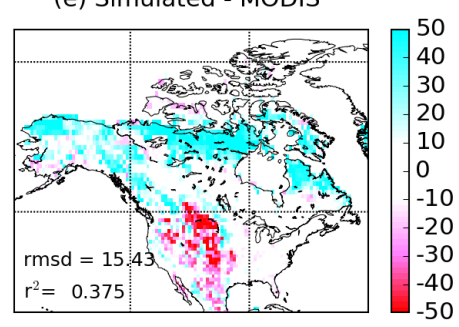

(f) MODIS - WANG06

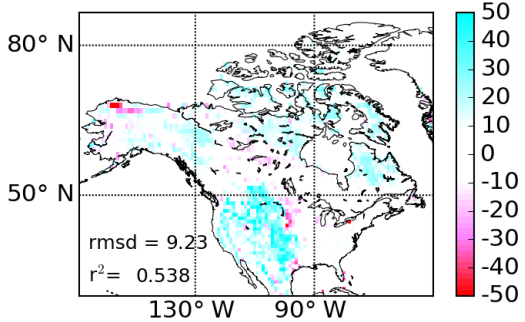

Figure 6. Spatial distribution of grass coverage across North America. Model-simulated results are shown in the left column (a) and the two observation-based estimates are shown in the middle column (b, d). The right column (c, e, f) shows the difference between modeland observation-based estimates (simulated minus WANG06 in c, and simulated minus MODIS in e), and the observation-based estimates themselves (MODIS minus WANG06 in $\mathbf{f}$ ) along with the root mean square difference (rmsd) and spatial correlation $\left(R^{2}\right)$ between the two estimates being compared.

\subsection{4 $\mathrm{C}_{3}$ and $\mathrm{C}_{4}$ grasses}

Figure $8 \mathrm{a}$ and $\mathrm{b}$ compare the simulated geographical distribution of $\mathrm{C}_{3}$ and $\mathrm{C}_{4}$ grasses with observation-based estimates.

In Fig. 8a, the most obvious limitation of the model is its excessive simulated grass coverage in Alaska and in Arctic Canada. Other than this, the model reproduces the broad geographical distribution of $\mathrm{C}_{3}$ grasses including the Great Plains of the US and the Canadian Prairies, where a large extent of grasslands is observed. The overestimated grass coverage at high latitudes leads to a total simulated $\mathrm{C}_{3}$ grass area $\left(4.4 \times 10^{6} \mathrm{~km}^{2}\right)$ that is higher than estimates based on the modified WANG06 $\left(1.9 \times 10^{6} \mathrm{~km}^{2}\right)$ and MODIS $\left(2.8 \times 10^{6} \mathrm{~km}^{2}\right)$ data sets. The spatial correlation and RMSD when comparing simulated coverage of $\mathrm{C}_{3}$ grasses to both observation-based estimates lie between 0.34 and 0.38 and between around 15 and $17 \%$, respectively. The spatial correlation and RMSD between the two observation-based estimates themselves are 0.54 and around $12 \%$, respectively.
Figure $8 \mathrm{~b}$ shows the distribution of $\mathrm{C}_{4}$ grasses which mostly occur in the tropics and do not occupy large areas in North America (as was also seen in Fig. 2b). The modelled geographical distribution of $\mathrm{C}_{4}$ grasses is larger than observation-based estimates, but the absolute fractions remain small so that the simulated area covered over the whole domain $\left(0.35 \times 10^{6} \mathrm{~km}^{2}\right)$ is actually smaller than estimates based on the modified WANG06 $\left(0.45 \times 10^{6} \mathrm{~km}^{2}\right)$ and MODIS $\left(0.7 \times 10^{6} \mathrm{~km}^{2}\right)$ data sets. The spatial correlation and RMSD when comparing simulated coverage of $\mathrm{C}_{4}$ grasses to both observation-based estimates lie between 0.12 and 0.16 and between around 3 and $5 \%$, respectively. The spatial correlation and RMSD between the two observation-based estimates themselves are 0.62 and around $5 \%$, respectively.

We do not compare the spatial distribution of broadleaf evergreen (BDL-EVG) and broadleaf drought deciduous (BDL-DCD-DRY) trees with the two observation-based estimates for three reasons: (1) the geographical distribution of these PFTs is limited to a small total area in our do- 


\section{Needleleaf evergreen tree}

(a) Simulated (1981-2010)
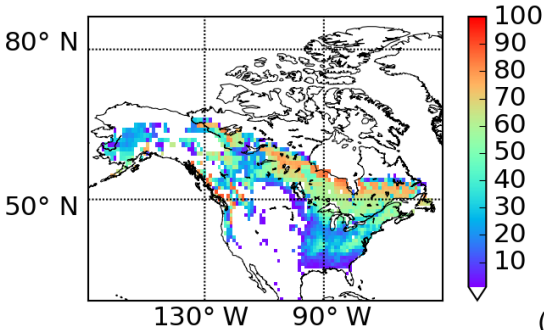

(b) Obs. (1981-2010) [WANG06]

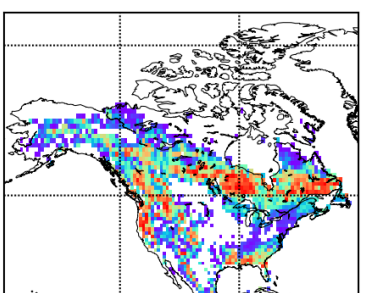

(d) Obs. (2001-2014) [MODIS]
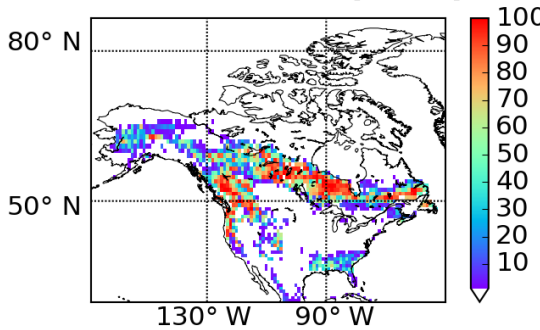

(c) Simulated - WANG06

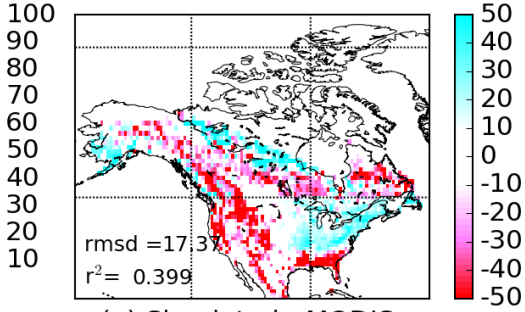

(e) Simulated - MODIS

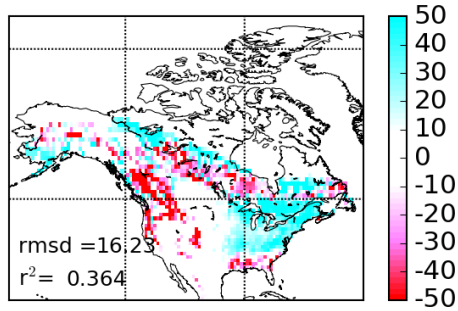

(f) MODIS - WANG06

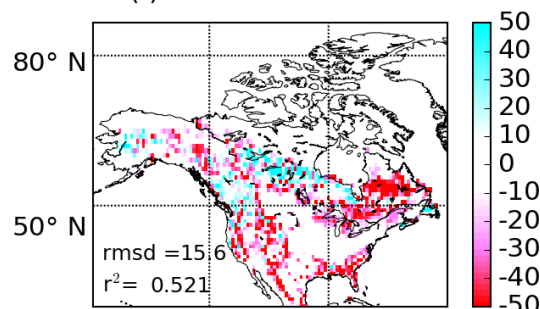

(c) Simulated - WANG06

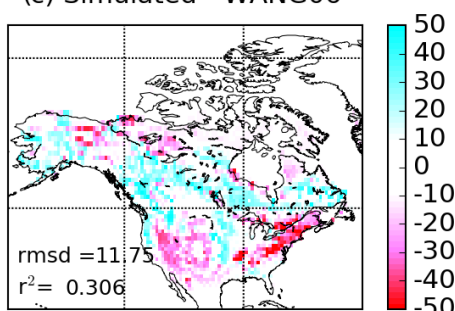

(e) Simulated - MODIS

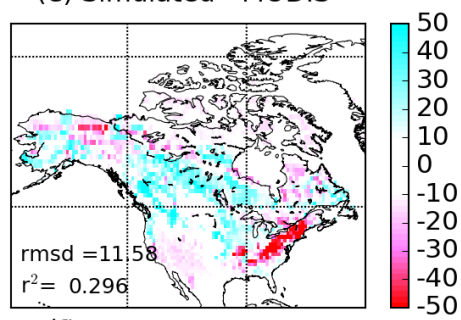

(f) MODIS - WANG06

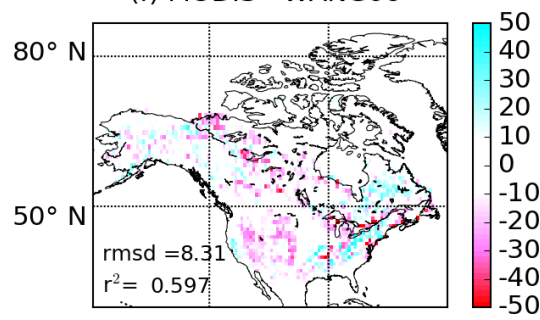

Figure 7. Spatial distribution of needleleaf trees (upper section) and broadleaf cold deciduous trees (lower section) across North America. Model-simulated results are shown in the left column (a) and the two observation-based estimates are shown in the middle column (b, d). The right column (c, e, f) shows the difference between model- and observation-based estimates (simulated minus WANG06 in c, and simulated minus MODIS in e), and the observation-based estimates themselves (MODIS minus WANG06 in $\mathbf{f}$ ) along with the root mean square difference (rmsd) and spatial correlation $\left(R^{2}\right)$ between the two estimates being compared. 
$\mathrm{C}_{3}$ grass

(a) Simulated (1981-2010)

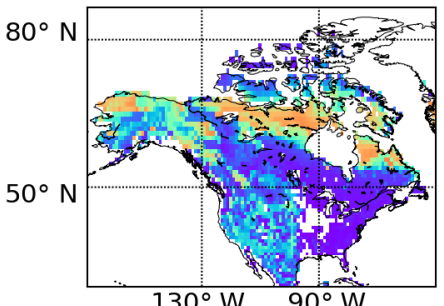

(b) Obs. (1981-2010) [WANG06]
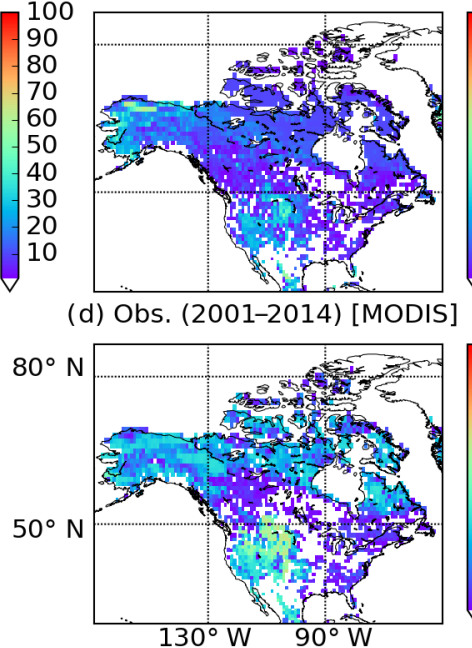

$30^{\circ} \mathrm{W} 90^{\circ} \mathrm{W}$

\section{$\mathrm{C}_{4}$ grass}

(a) Simulated (1981-2010)

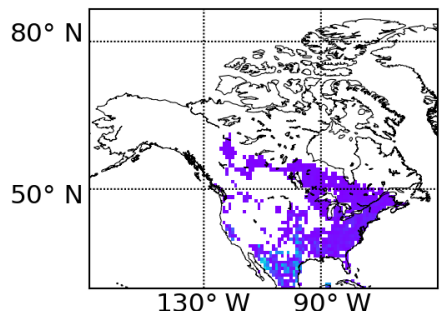

$130^{\circ} \mathrm{W} 90^{\circ} \mathrm{W}$ (b) Obs. (1981-2010) [WANG06]

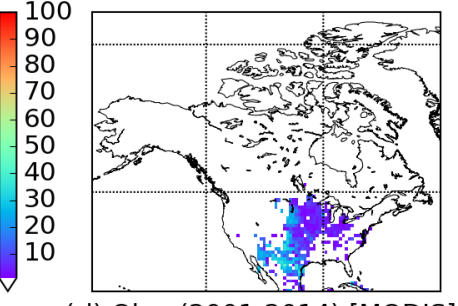

(d) Obs. (2001-2014) [MODIS]

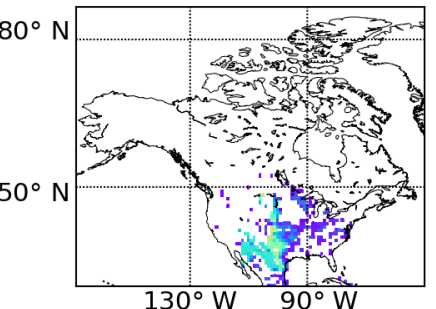

(c) Simulated - WANG06

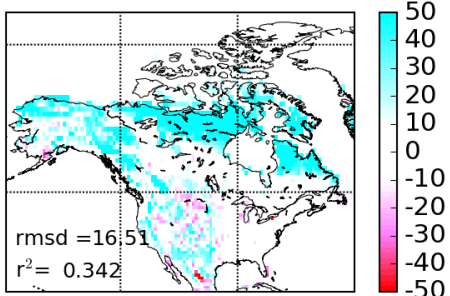

(e) Simulated - MODIS

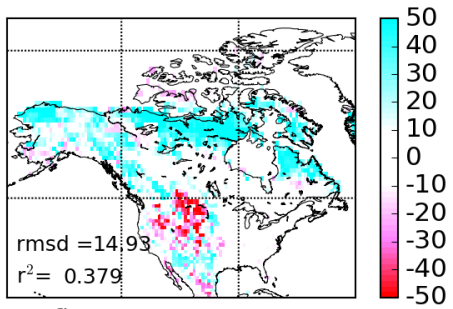

(f) MODIS - WANG06

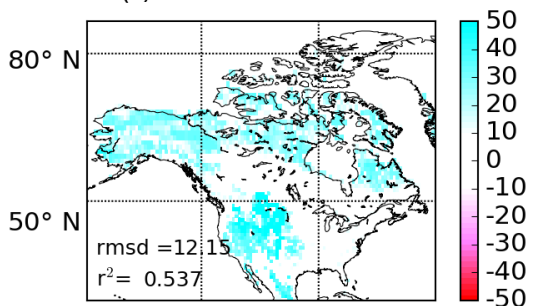

(c) Simulated - WANG06

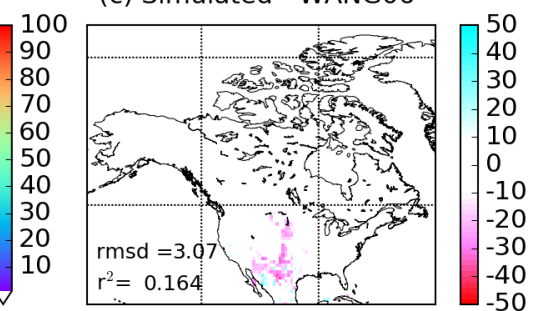

(e) Simulated - MODIS
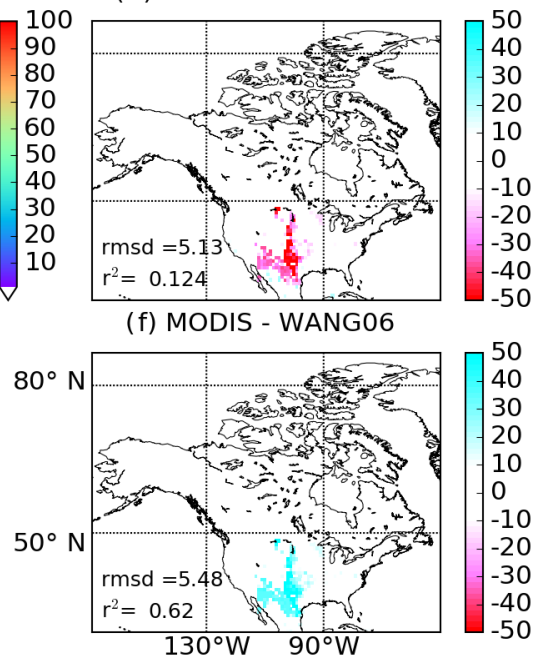

Figure 8. Spatial distribution of $\mathrm{C}_{3}$ grasses (upper section) and $\mathrm{C}_{4}$ grasses (lower section) across North America. Model-simulated results are shown in the left column (a) and the two observation-based estimates are shown in the middle column (b, d). The right column (c, e, f) shows the difference between model- and observation-based estimates (simulated minus WANG06 in c, and simulated minus MODIS in e), and the observation-based estimates themselves (MODIS minus WANG06 in $\mathbf{f}$ ) along with the root mean square difference (rmsd) and spatial correlation $\left(R^{2}\right)$ between the two estimates being compared. 
main; (2) the geographical distribution of the BDL-EVG tree PFT based on observations cannot be directly compared to simulated values because, when mapping land cover types to CTEM PFTs in WANG06, evergreen shrubs (which exist much farther north than $30^{\circ} \mathrm{N}$ ) are assigned to the BDL-EVG tree PFT; and (3) the geographical distribution of the BDLDCD-DRY tree PFT in the observation-based data sets is based on the arbitrary latitudinal thresholds of 24 and $34^{\circ} \mathrm{N}$ as mentioned earlier.

\subsection{LAI and GPP}

Figure 9 compares the geographical distribution of simulated LAI and GPP with observation-based estimates for the present day. In Fig. 9a, the simulated geographical distribution of LAI compares well with the observation-based estimates. The spatial correlation and RMSD between simulated and observation-based estimates are 0.74 and $0.81 \mathrm{~m}^{2} \mathrm{~m}^{-2}$ (the $\mathrm{m}^{2} \mathrm{~m}^{-2}$ unit implies $\mathrm{m}^{2}$ of leaf area per $\mathrm{m}^{2}$ of ground area), respectively. The domain-averaged simulated LAI of $2.5 \mathrm{~m}^{2} \mathrm{~m}^{-2}$ is higher than the observation-based estimate of $2.1 \mathrm{~m}^{2} \mathrm{~m}^{-2}$. The model captures the broad geographical patterns with higher LAI over the boreal forest region in Canada and also in the eastern US similar to observations. However, some differences remain particularly over the drier southwest US where the model simulates bare ground with negligible LAI but observations suggest a small LAI of around $1 \mathrm{~m}^{2} \mathrm{~m}^{-2}$. In contrast, the model slightly overestimates LAI over Northern and Arctic Canada where it simulates a higher fractional coverage of $\mathrm{C}_{3}$ grasses, as seen earlier.

Consistent with the geographical distribution of LAI, the simulated GPP is overestimated in the eastern US and the Canadian boreal forest (Fig. 9b). The broad geographical distribution of GPP, similar to LAI, is consistent with the observation-based estimates. The spatial correlation and RMSD between simulated and observation-based estimates are 0.78 and $225 \mathrm{~g} \mathrm{C} \mathrm{m}^{-2} \mathrm{yr}^{-1}$, respectively. The domainaveraged simulated GPP of $737 \mathrm{~g} \mathrm{Cm}^{-2} \mathrm{yr}^{-1}$ is higher than the observation-based estimate of $628 \mathrm{~g} \mathrm{Cm}^{-2} \mathrm{yr}^{-1}$. As with LAI, the simulated GPP is lower than observations over the drier southwest region of the US where the model simulates more bare ground than observation-based estimates, and the model overestimates GPP over Northern and Arctic Canada.

Figure 10 shows the time series of annual domainaveraged GPP, LAI, net primary productivity and domainsummed net biome productivity (NBP). The NBP term is essentially the net atmosphere-land $\mathrm{CO}_{2}$ flux which is the result of all terrestrial ecosystem processes including photosynthesis, autotrophic and heterotrophic respiration, fire and land use change. NBP values of zero indicate that the system is in equilibrium such that carbon gained by photosynthesis is equal to carbon lost by respiration and other processes. Simulated GPP, LAI and NPP all show an increase over the 20th century due to the increase in atmospheric $\mathrm{CO}_{2}$ concentration and the associated change in climate. The in- crease in $\mathrm{CO}_{2}$ drives the increase in GPP and subsequently in NPP and LAI through the $\mathrm{CO}_{2}$ fertilization effect. The net result of this gradually increasing NPP is that the terrestrial ecosystems become a sink of carbon, and this is seen in the resulting positive values of NBP. The simulated sink over the North American domain for the periods 1990-2000 and 2000-2010 is around 0.4 and $0.5 \mathrm{PgC} \mathrm{yr}^{-1}$, respectively. Crevoisier et al. (2010) compare the carbon sink over the North American region from five studies (their Table 1) for time periods in the 1990s and 2000s. These reported sinks vary from $0.81 \pm 0.72$ to $1.26 \pm 0.23 \mathrm{Pg} \mathrm{Cyr}^{-1}$ for the period 1992-1996 and $0.58 \mathrm{PgC} \mathrm{yr}^{-1}$ for the period 2001-2006, and Crevoisier et al. (2010) themselves estimate a value of $0.51 \pm 0.41 \mathrm{PgC} \mathrm{yr}^{-1}$ for the period 2004-2006. The sinks simulated by CLASS-CTEM over the 1990s and 2000s are broadly consistent with these estimates.

\subsection{Added value of finer spatial resolution}

Figure 11 assesses the added value of running the model and performing competition between PFTs at the $1^{\circ}$ spatial resolution used in this study compared to the $3.75^{\circ}$ resolution used in the Melton and Arora (2016) study which evaluated the performance of CLASS-CTEM's competition module at the global scale. For Fig. 11, the Melton and Arora (2016) results were extracted for the North American domain used in this study, and observation-based estimates of fractional coverage of tree, grass and total vegetation from the modified WANG06 land cover product were re-gridded to the $3.75^{\circ}$ resolution. The resulting spatial correlations and RMSDs between the simulated and the WANG06 estimates for fractional coverage of tree, grass and total vegetation, at the two spatial resolutions, are summarized in Fig. 11. When compared to the modified WANG06 data the RMSDs are somewhat lower (Fig. 11a), and spatial correlations (Fig. 11b) are slightly higher for the model's implementation at $3.75^{\circ}$ resolution, compared to the model's implementation at $1^{\circ}$ resolution. This indicates that the model's performance is slightly better at the coarser $3.75^{\circ}$ resolution. Recall that competition between PFTs occurs over the non-crop fraction of each grid cell. For this reason, we do not perform this analysis for the MODIS-based land cover product because the crop areas that are specified in the model are exactly the same as those in the modified WANG06 land cover product, making comparison of simulated and observation-based fractional coverages of PFTs more consistent for the modified WANG06 land cover product.

\section{Discussion}

Competition between PFTs, which determines their fractional coverage, is one of the several processes that the CLASS-CTEM modelling framework simulates. Other than competition between PFTs, terrestrial ecosystem processes 
Grid-averaged LAI

(a) Simulated (1980-2010)

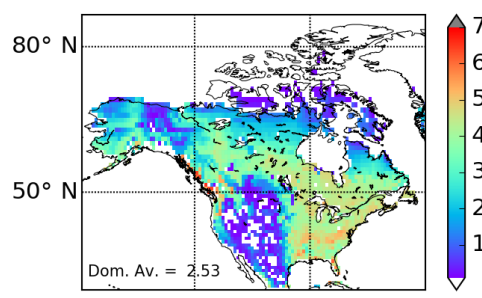

(b) Observed (1981-2010)

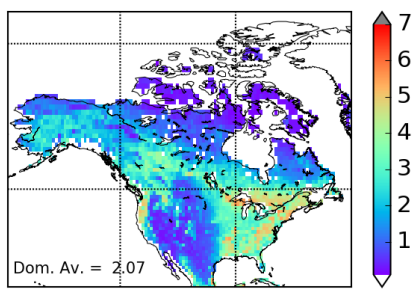

(c) Simulated - observed

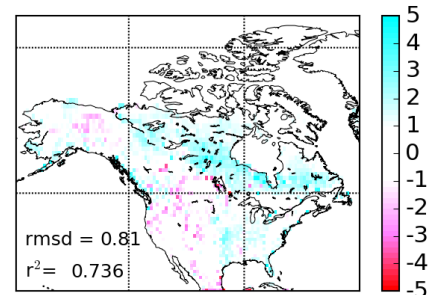

\section{Grid-averaged GPP}

(a) Simulated (1980-2010)

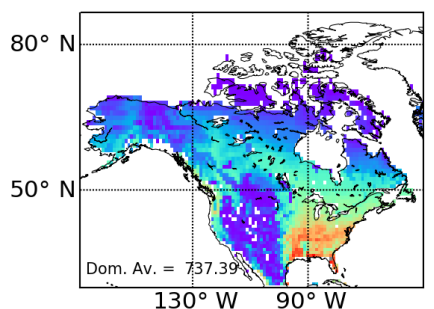

(b) Observed (1982-2008)

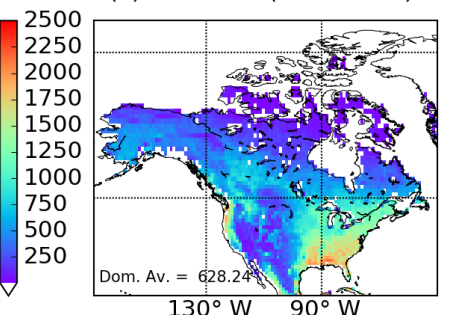

(c) Simulated - observed

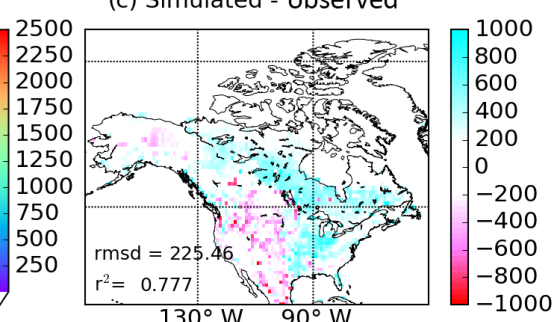

Figure 9. Spatial distribution of grid-averaged maximum LAI $\left(\mathrm{m}^{2} \mathrm{~m}^{-2}\right)$ (upper row) and grid-averaged GPP $\left(\mathrm{gC} \mathrm{m}^{-2} \mathrm{yr}^{-1}\right)(\mathrm{bottom} \mathrm{row})$ across North America. Simulated values are shown in (a), observation-based values in (b) and differences between them are shown in (c), which also shows the root mean square difference $(\mathrm{rmsd})$ and spatial correlation $\left(R^{2}\right)$ between simulated and observation-based values.
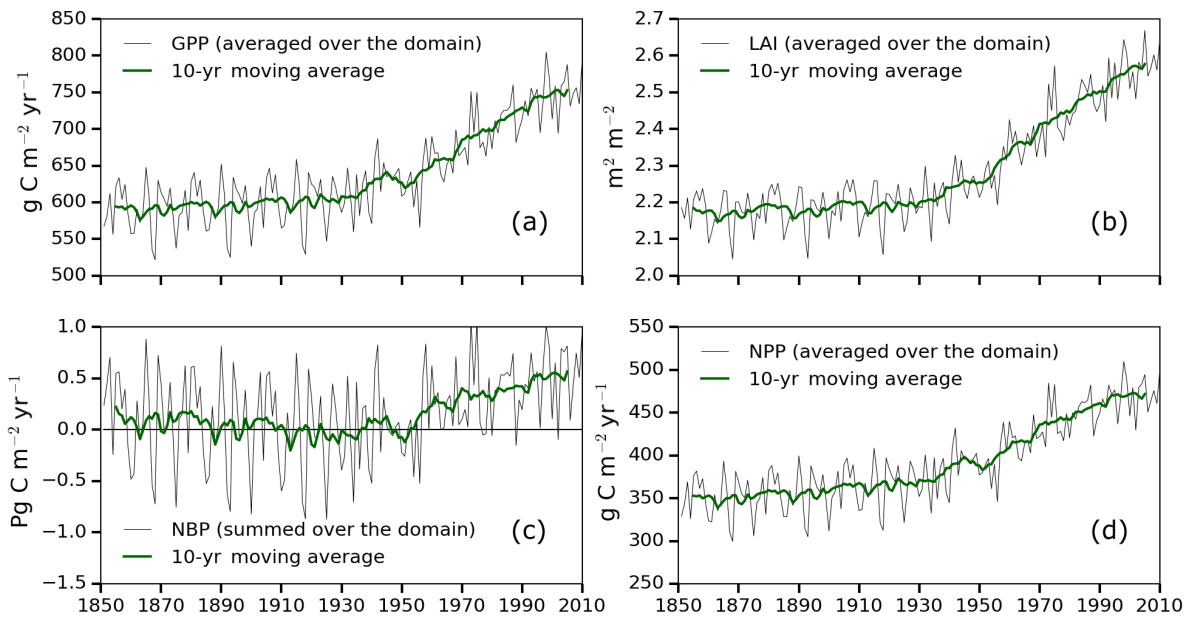

Figure 10. Time series evolution of (a) domain-averaged GPP $\left(\mathrm{g} \mathrm{Cm}^{-2} \mathrm{yr}^{-1}\right)$, (b) domain-averaged LAI $\left(\mathrm{m}^{2} \mathrm{~m}^{-2}\right),(\mathbf{c})$ domain total NBP $\left(\mathrm{Pg} \mathrm{Cm}^{-2} \mathrm{yr}^{-1}\right)$ and (d) domain-averaged NPP $\left(\mathrm{g} \mathrm{Cm}^{-2} \mathrm{yr}^{-1}\right)$.

of photosynthesis, autotrophic and heterotrophic respiration, allocation of carbon from leaves to stem and root components, dynamic leaf phenology, fire and land use change are also modelled. These aspects of the model have been evaluated at point (Arora, 2003; Arora and Boer, 2005; Melton et al., 2015), regional (Garnaud et al., 2015; Peng et al., 2014; Arora et al., 2016) and global (Arora and Boer, 2010; Melton and Arora, 2014, 2016) scales. A typical model evaluation exercise at the global scale compares model-simulated geographical and latitudinal distribution of GPP, vegetation biomass, and soil carbon with their respective observationbased estimates such as those from Beer et al. (2010), Ruesch and Holly (2008), and the Harmonized World Soil Database (FAO/IIASA/ISRIC/ISS-CAS/JRC, 2012). Model evaluation exercises help in identifying model limitations but also yield opportunities to improve model performance by tuning model parameters. The CLASS-CTEM model also participated in the 2016 TRENDY intercomparison of terrestrial ecosystem models whose results contributed to the global carbon project (Le Quéré et al., 2016). The competi- 
(a) RMSD

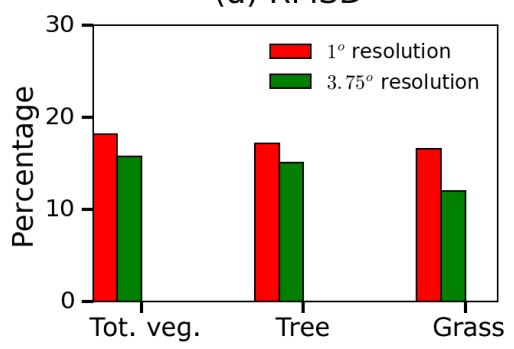

(b) $R^{2}$

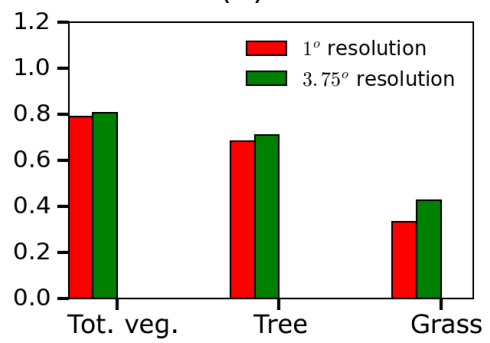

Figure 11. Comparison of the performance of the model at the $1^{\circ}$ spatial resolution in this study with that at the $3.75^{\circ}$ spatial resolution in the Melton and Arora (2016) study. The Melton and Arora (2016) global results were extracted for the North American domain. Spatial correlations and root mean square differences are used as metrics for the comparison between simulated and the observation-based estimate based on the modified WANG06 land cover product for fractional coverage of total vegetation, tree and grass.

tion module of the CLASS-CTEM modelling framework has been previously evaluated at point scales (Arora and Boer, 2006; Shrestha et al., 2016). In addition to assessing fractional coverage at which PFTs equilibrate, these point-scale evaluations also assess the time the PFTs take to reach their equilibrium fractional coverages against empirical data and whether the succession patterns are realistically simulated (e.g. grasses should colonize a given area before trees invade the area covered by grasses). This paper focusses on evaluation of the competition module of the CLASS-CTEM modelling framework at a regional scale.

Dynamically simulated fractional coverages of PFTs add another degree of freedom to a model compared to the case where the fractional coverages of its PFTs are specified. This is a more stringent test of a model's performance. Errors in the simulated geographical distribution of PFTs will, of course, lead to corresponding errors in the geographical distribution of primary terrestrial ecosystem carbon pools and fluxes. Yet, the CLASS-CTEM model is broadly able to reproduce the geographical distributions of GPP and LAI. Limitations, of course, remain. In particular, the simulated LAI and GPP are high in Alaska and in Northern and Arctic Canada, and these variables are lower than their observationbased estimates in arid regions of the western US. The simulated fractional vegetation coverage reflects these patterns.

It is difficult to conclusively determine whether these model limitations are due to the limitations in the biogeochemistry parameterizations of the model for its existing PFTs or the simple structural limitation that the model does not represent shrub, moss and lichen PFTs. Shrubs are adapted to grow in arid and semi-arid regions, whether in cold or hot climates (where neither grasses nor trees are able to grow), and their representation in the model would likely help to increase the fractional vegetation cover in arid regions including those in the western US. At high latitudes grass growth is inhibited by mosses and lichens which flourish in cold and damp conditions. A representation of moss and lichen PFTs and improved representation of permafrost in the model would likely help to decrease simulated grass cover- age in Arctic regions. In the current version of the CLASSCTEM model bioclimatic limits are used only for tree PFTs to ensure that these PFTs do not venture outside their predetermined bioclimatic zones. In the model, bioclimatic limits are not used for grasses, and their geographical distribution is entirely the result of plant physiological processes and their competitive interactions with the tree PFTs and amongst themselves. Since, in the Arctic region, grasses do not face competition from tree PFTs, and moss and lichen PFTs are not represented in the model, they are free to increase their expanse - climate permitting, of course. Another possible reason for higher-than-observed grass coverage in the Arctic region is that in the current implementation of CLASS only three permeable soil layers with maximum thicknesses of $0.1,0.25$ and $3.75 \mathrm{~m}$ are represented, and a boundary condition of zero heat flux is assumed across the bottommost layer. This simple representation does not allow modelling permafrost realistically. Permafrost is more realistically modelled with multiple permeable and impermeable (extending into the bed rock) layers that go sufficiently deep ( $>30 \mathrm{~m}$ at least) to capture the slow evolution of soil temperatures in response to climate warming (Teufel et al., 2017). The current setup of three layers that go only $4.1 \mathrm{~m}$ deep produces soil temperatures that are warmer than in the setup when permeable and impermeable layers are sufficiently deep and produces permafrost extent that is lower than observation-based estimates (Koven et al., 2013). It is likely that warmly biased soil temperatures in the current setup contribute to promote grass growth and allow it to cover a larger area in the Arctic region than would be the case when permafrost is more realistically modelled.

The lower-than-observed fractional vegetation cover in the arid and semi-arid regions of the western US, however, may not solely be due to model limitations alone. Here, we argue that the manner in which remotely sensed land cover types are mapped to CTEM PFTs and the errors in calculating bare ground fraction in remotely sensed products also contribute to the mismatch between modelled and observationbased values of fractional vegetation cover. We illustrate this 
(a) Simulated

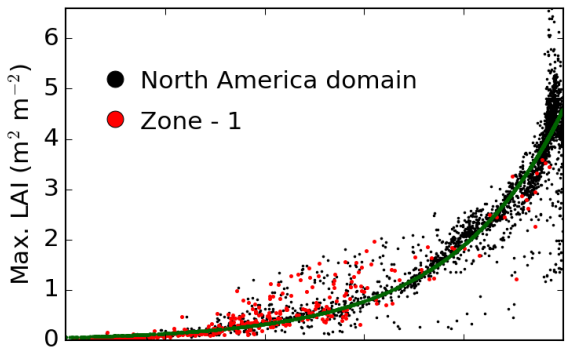

(c) Observed LAI vs. WANG06 PFT fraction

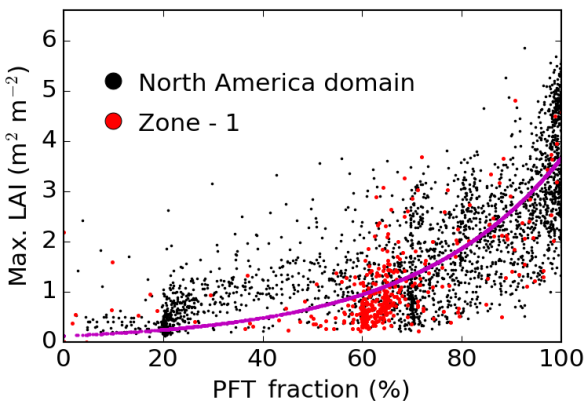

(b) Observed LAI vs. MODIS PFT fraction

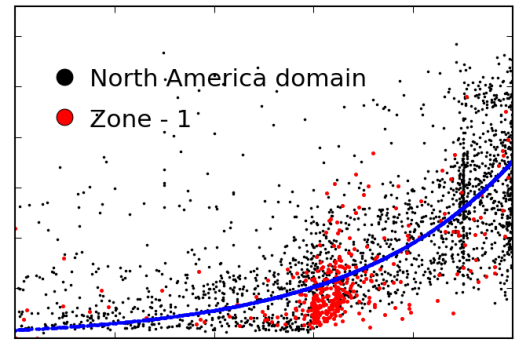

(d) Comparison of trends

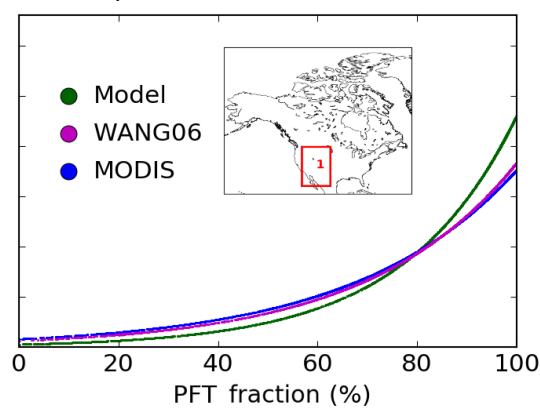

Figure 12. Scatterplots of (a) simulated LAI vs. simulated total vegetation coverage, (b) observed LAI vs. MODIS-derived total vegetation coverage and (c) observed LAI vs. WANG06 total vegetation coverage. (d) Comparison of the fitted curves represented by solid lines, with an inset map of North America showing the subdomain of interest bounded by a red rectangle.

by comparing the functional relationship between LAI and total vegetation cover. Figure 12a shows this relationship for model-simulated values. As expected, as LAI increases so does the total vegetation cover. The relationship between these two variables is fairly tight in the model, and the green line is an exponential fit. The red dots in the figure correspond to grid cells that lie in the region identified in the inset in Fig. 12d and broadly correspond to the western half of the US. Figure $12 \mathrm{~b}$ and $\mathrm{c}$ show the same relationship but between the observation-based estimate of LAI from Zhu et al. (2013) (as mentioned in Sect. 2.3.2) and the total vegetation cover based on the WANG06- and MODIS-derived land cover data sets, respectively. The blue and magenta lines in Fig. $12 \mathrm{~b}$ and $\mathrm{c}$ are the corresponding exponential fits. When compared with Fig. 12a, Fig. 12b and c show much more scatter around the fitted curves, and the overall relationship appears to break down for the red dots corresponding to the grid cells in the western US. A careful look at the red dots in Fig. $12 \mathrm{~b}$ and $\mathrm{c}$ shows that the observation-based vegetation cover in the western US for a large fraction of grid cells is around $60 \%$ regardless of the observation-based LAI which ranges between 0.1 and $1.5 \mathrm{~m}^{2} \mathrm{~m}^{-2}$. Clearly, it is physically unrealistic to achieve fractional vegetation coverage of $60 \%$ below LAI values of $0.6 \mathrm{~m}^{2} \mathrm{~m}^{-2}$, and this indicates that the fractional vegetation cover in this region is likely overestimated in both observation-based data sets.

There are at least two ways in which errors in total vegetation cover can occur. The first relates to the method by which the fractional vegetation cover is calculated for the land cover types in the original remotely sensed land cover products that is, for the 22 land cover types in the GLC2000 data set upon which the WANG06 data are based and the 17 land cover types in the MODIS data set. An example of such an error for arid regions is illustrated by Lawley et al. (2014), who suggest that the MODIS soil fractional cover product, at least in its present form, is unsuited to monitoring sparsely vegetated arid landscapes and generally unable to separate soil from vegetation in situations where NDVI is low. The second way in which errors are introduced is through the mapping of the remotely sensed land cover types to the CTEM PFTs following Table 2 of WANG06 for the GLC2000 land cover types, and following Table 2 in this paper for the MODIS land cover types. This mapping is based on available information in the literature but is also based on expert judgement, which introduces subjectiveness. For instance, it is debatable what fraction of the "open shrublands" MODIS land cover type, which exists over much of the arid southwestern US, is in fact bare ground. In Table 2, we have allocated a fraction of 0.4 of open shrublands to bare ground following WANG06. Had WANG06 allocated a higher value than this to bare ground, our simulated values would have compared better with the observation-based values of bare ground fraction over arid regions. Nevertheless, this would not have changed the relationship, or rather the lack thereof, between the observation-based estimates of LAI and the total vegetation cover in the western half of the US seen in Fig. $12 b$ and c. 
Both model and observation-based results are also affected by a common limitation associated with peatlands which exists in the Hudson Bay lowlands region. Both the GLC2000 data set, upon which the modified WANG06 land cover product is based, and the MODIS land cover data do not represent peatland vegetation. In these data sets the peatland vegetation is classified either as grasses, shrubs or trees. The model also does not represent peatlands, and as a result the model grows trees and grasses in regions where peatlands exists. Work is under way to incorporate a peatland model developed for CLASS-CTEM (Wu et al., 2016) into our modelling framework.

The simulated areas covered by the primary two tree PFTs (NDL-EVG and BDL-DCD-COLD) have their weaknesses, but large differences also exist between the two observationbased estimates especially for the NDL-EVG PFT. Modelling competition between two tree PFTs is much more difficult than between trees and grasses. In the latter case trees are always considered superior to grasses, but in the case of competition between two tree PFTs the superiority is based on parameterized colonization rates which depend on simulated NPP. Based on comparisons with observation-based estimates, the main limitation in model results here is that the model overestimates the coverage of NDL-EVG trees and underestimates the coverage of BDL-DCD-COLD trees in the eastern US, while the opposite is true in western Canada. The model, of course, does not represent individual species, while in the real world competition occurs at the species level that is modulated by soils and nutrient availability. An example that illustrates this limitation of the model is the jack pine tree species which occupies the ecological niche of nutrientpoor soils in boreal Canada (e.g. see Ste-Marie et al., 2007). The coupling of carbon and nutrient cycles is currently not represented in CLASS-CTEM, and optimizing model parameters for hundreds of species is currently extremely difficult given limited available data at the species level. Most likely before the model is applied at the species level, as a first step, the number of PFTs represented in the model should be increased. An example of how additional PFTs in the CLASS-CTEM framework can lead to improved model performance is illustrated by Peng et al. (2014). This application of the model shows how subdividing the NDL-EVG PFT into coastal and interior types for the province of British Columbia in Canada leads to improvement in simulated LAI and GPP. A recent attempt to explicitly represent physiological processes in a model to simulate competition between needleleaf and broadleaf cold deciduous trees at a regional scale is illustrated in Fisher et al. (2015), who incorporated the concepts from the Ecosystem Demography (ED) model into the community land model-dynamic global vegetation model (CLM-DGVM). Their results provide some interesting insights; however, validation of this approach at the global scale over a wide range of PFTs remains challenging.

Finally, one of the objectives of this study was to evaluate whether resolving climate niches by performing CLASS-
CTEM simulation at a finer resolution of $1^{\circ}$ in this study allowed improved simulation of the geographical distribution of PFTs than in the Melton and Arora (2016) study that evaluated the competition module of the CLASS-CTEM model at $3.75^{\circ}$ spatial resolution at the global scale. Figure 11 addresses this objective and shows that, while the spatial correlations and RMSDs between the simulated and the modified WANG06 land cover product for fractional coverage of tree, grass and total vegetation are fairly similar for the model outputs at $1^{\circ}$ and $3.75^{\circ}$ resolutions, these metrics are somewhat better for the model's application at the coarser $3.75^{\circ}$ resolution. One possible reason for the slightly worse model performance at the finer resolution is that while climate niches are resolved better at the finer resolution the model does not have the additional differentiation in PFTs (the number of model PFTs is still nine) that is required to gain benefit from the resolved climate niches. In addition, comparing Melton and Arora (2016) results over North America with ones obtained here we note that the primary model limitations remain unchanged in the application of the model at both spatial resolutions. These include lower simulated fractional vegetation coverage in the arid southwest North American region and higher in the Arctic region (due to higher grass coverage). In addition, in both applications of the model the differences in simulated geographical distribution of NDL-EVG and BDL-DCD-CLD PFTs, compared to the WANG06 land cover data, are also similar. Model differences, compared to the WANG06 data, therefore remain more or less similar in the application of the model at both spatial resolutions. These results are, however, based on offline applications of the CLASS-CTEM model where it is driven by reanalysis data. In a fully coupled simulation where CLASS-CTEM is coupled to an atmospheric model it is possible that model performance at low spatial resolution is different from its performance at high spatial resolution

The comparison between observation-based and simulated fractional coverages is the most robust at the basic treegrass-bare ground level. The subjectiveness introduced in the process of mapping remotely sensed land cover types to the PFTs represented in a model, as mentioned above, makes the comparison of simulated and observation-based fractional coverages for individual PFTs less robust. Nevertheless, comparisons with observations allow useful insights into model limitations as we have seen here.

\section{Summary and conclusions}

This study evaluates the CLASS-CTEM-simulated fractional coverages of PFTs, when driven with observed meteorological forcing, against the observation-based estimates from MODIS and the modified WANG06 data sets over the North American region. In the past, performance of the competition module of the CLASS-CTEM modelling framework has been assessed at a global scale, at a coarse spatial resolu- 
tion of $3.75^{\circ}$ (Melton and Arora, 2016), as well as at a point scale, for a range of locations across the globe (Shrestha et al., 2016). Our objective here was to assess the performance of the CLASS-CTEM competition module at a higher spatial resolution of $1^{\circ}$ over North America. To achieve this objective we compared simulated present-day geographical distributions of fractional coverages of PFTs, but also LAI and GPP, with their observation-based estimates.

The CLASS-CTEM modelling framework is generally able to reproduce the dominant features of the geographic distribution of PFT coverage and LAI and GPP over the North American region. After 1960, the model simulates increasing GPP and LAI in response to changing climate as well as increased atmospheric $\mathrm{CO}_{2}$ concentrations, and the resulting sink for the 1990s and 2000s is broadly consistent with other estimates.

The simulated geographical distribution of PFTs, when compared to observation-based estimates, shows two primary limitations, which are excessive grass cover in the Arctic region and low vegetation cover in the arid western US, although for the latter the observation-based estimates themselves may have their own weaknesses. There are three main factors in the CLASS-CTEM modelling framework that may have contributed to these differences: (1) the absence of a shrub PFT, which we believe is the reason for low simulated vegetation coverage in the arid to semi-arid western United States; (2) the absence of moss and lichen PFTs that may inhibit the establishment of grasses; and (3) probably a lack of sensitivity of $\mathrm{C}_{3}$ grasses to high-latitude climate and an inadequate representation of permafrost. Future model developments will focus on these aspects with a view to improving model performance.

Data availability. The model code is available at https://gitlab. com/jormelton/classctem but requires setting up an account on gitlab.com. Once this is done please drop an email to joe.melton@canada.ca with your gitlab.com username to obtain access. The model results can be obtained from vivek.arora@canada.ca.

Competing interests. The authors declare that they have no conflict of interest.

Acknowledgements. The authors would like to thank Paul Bartlett and Reinel Sospedra-Alfonso for providing their comments on an earlier version of this paper. The authors would also like to thank the handling editor and the two anonymous reviewers for their help and their feedback on the manuscript. We are also grateful to Nicholas Viovy for putting together the CRU-NCEP meteorological data. The first author was supported by funds from the National Scientific and Engineering Research Council (NSERC) through funding of the Canadian Network for Regional Climate and Weather Processes (CNRCWP).
Edited by: Alexey V. Eliseev

Reviewed by: two anonymous referees

\section{References}

Anav, A., Friedlingstein, P., Kidston, M., Bopp, L., Ciais, P., Cox, P., Jones, C., Jung, M., Myneni, R., and Zhu, Z.: Evaluating the land and ocean components of the global carbon cycle in the CMIP5 earth system models, J. Climate, 26, 6801-6843, https://doi.org/10.1175/JCLI-D-12-00417.1, 2013.

Arora, V. K.: Land surface modelling in general circulation models: a hydrological perspective, $\mathrm{PhD}$ Thesis, University of Melbourne, Melbourne, Australia, 1997.

Arora, V. K.: Simulating energy and carbon fluxes using coupled land surface and terrestrial ecosystem models, Agr. Forest Meteorol., 118, 21-47, 2003.

Arora, V. K. and Boer, G. J.: A representation of variable root distribution in dynamic vegetation models, Earth Interact., 7, 1-19, 2003.

Arora, V. K. and Boer, G. J.: A parameterization of leaf phenology for the terrestrial ecosystem component of climate models, Glob. Change Biol., 11, 39-59, 2005.

Arora, V. K. and Boer, G. J.: Simulating competition and coexistence between plant functional types in a dynamic vegetation model, Earth Interact., 10, 1-29, 2006.

Arora, V. K. and Boer, G. J.: Uncertainties in the 20th century carbon budget associated with land use change, Global Change Biol., 16, 3327-3348, 2010.

Arora, V. K., Boer, G. J., and Friedlingstein, P. E. A.: Carbonconcentration and carbon-climate feedbacks in CMIP5 earth system models, J. Climate, 26, 5289-5314, 2013.

Arora, V. K., Peng, Y., Kurz, W. A., Fyfe, J. C., Hawkins, B., and Werner, A. T.: Potential near-future carbon uptake overcomes losses from a large insect outbreak in British Columbia, Canada, Geophys. Res. Lett., 43, 2590-2598, https://doi.org/10.1002/2015GL067532, 2016.

Beer, C., Reichstein, M., Tomelleri, E., Ciais, P., Jung, M., Carvalhais, N., Rodenbeck, C., Arain, M. A., Baldocchih, D., Bonan, G. B., Bondeau, A., Cescatti, A., Lasslop, G., Lindroth, A., Lomas, M., Luyssaert, S., Margolis, H., Oleson, K. W., Roupsard, O., Veenendaal, E., Vivoy, N., Williams, C., Woodward, F. I., and Papale, D.: Terrestrial gross carbon dioxide uptake: global distribution and covariation with climate, Science, 329, 834-838, https://doi.org/10.1126/science.1184984, 2010.

Bonan, G. B.: Forests and climate change: forcings, feedbacks, and the climate benefits of forests, Science, 320, 1444-1449, https://doi.org/10.1126/science.1155121, 2008.

Box, E. O.: Plant functional types and climate at the global scale, J. Veg. Sci., 7, 309-320, https://doi.org/10.2307/3236274, 1996.

Brentnall, S. J., Beerling, D. J., Osborne, C. P., Harland, M., Francis, J. E., Valdes, P. J., and Wittig, V. E.: Climatic and ecological determinants of leaf lifespan in polar forests of the high $\mathrm{CO}_{2}$ Cretaceous "greenhouse" world, Global Change Biol., 11, 21772195, 2005.

Broxton, P., Zeng, X., Sulla-Menashe, D., and Troch, P.: A global land cover climatology using MODIS data, J. Appl. Meteo- 
rol. Clim., 53, 1593-1605, https://doi.org/10.1175/JAMC-D-130270.1, 2014.

Cox, P.: Description of the "TRIFFID” Dynamic Global Vegetation Model, Tech. Note 24, Hadley Centre, Met Office, UK, 2001.

Cramer, W., Bondeau, A., Woodward, F. I., Prentice, I. C., Betts, R. A., Brovkin, V., Cox, P. M., Fisher, V., Falloon, P. D., Foley, J., Friend, A. D., Kucharik, C., Lomas, M. R., Ramankutty, N., Sitch, S., Smith, B., White, A., and MollingYoung, C.: Global response of terrestrial ecosystem structure and function to $\mathrm{CO}_{2}$ and climate change: results from six dynamic global vegetation models, Global Change Biol., 7, 357373,2001

Crevoisier, C., Sweeney, C., Gloor, M., Sarmiento, J. L., and Tans, P. P.: Regional US carbon sinks from the three-dimensional atmospheric $\mathrm{CO}_{2}$ sampling, P. Natl. Acad. Sci. USA, 107, 18348-18353, https://doi.org/10.1073/pnas.0900062107, 2010.

FAO/IIASA/ISRIC/ISS-CAS/JRC: Harmonized World Soil Database (version 1.2), available at: http://www.fao. org/soils-portal/soil-survey/soil-maps-and-databases/

harmonized-world-soil-database-v12/en/ (last access: 20 January 2016), 2012.

Fisher, R. A., Muszala, S., Verteinstein, M., Lawrence, P., Xu, C., McDowell, N. G., Knox, R. G., Koven, C., Holm, J., Rogers, B. M., Spessa, A., Lawrence, D., and Bonan, G.: Taking off the training wheels: the properties of a dynamic vegetation model without climate envelopes, CLM4.5(ED), Geosci. Model Dev., 8, 3593-3619, https://doi.org/10.5194/gmd-8-3593-2015, 2015.

Friedl, M., Strahler, A., Schaaf, C., Hodges, J. C. F., and Salomon, J.: Binary MODIS MOD12C1 0.25 Degree Land Cover Climate Modeler Grid, Department of Geography, Boston University, Boston, Massachusetts, USA, available at: https://lpdaac.usgs.gov/dataset_discovery/modis/modis_ products_table/mcd12c1 (last access: 21 July 2015), 2013.

Friedlingstein, P., Cox, P., Betts, R., Bopp, L., Von Bloh, W., Brovkin, V., Cadule, P., Doney, S., Eby, M., Fung, I., Bala, G., John, J., Jones, C., Joos, F., Kato, T., Kawamiya, M., Knorr, W., Lindsay, K., Matthews, H. D., Raddatz, T., Rayner, P., Reick, C., Roeckner, E., Schnitzler, K.-G., Schnur, R., Strassmann, K., Weaver, A. J., Yoshikawa, C., and Zeng, N.: Climate-carbon cycle feedback analysis: results from the C4MIP model intercomparison, J. Climate, 19, 3337-3353, 2006.

Friend, A. D., Chard, Lucht, W., Rademacher, T., Keribin, R., Betts, R., Cadule, P., Ciais, P., Clark, D. B., Dankers, R., Falloon, P. D., Ito, A., Kahana, R., Kleidon, A., Lomas, M. R., Nishina, K., Ostberg, S., Pavlick, R., Peylin, P., Schaphoff, S., Vuichard, N., Warszawski, L., Wiltshire, A., and Woodward, F. I.: Carbon residence time dominates uncertainty in terrestrial vegetation response to future climate and atmospheric $\mathrm{CO}_{2}$, P. Natl. Acad. Sci. USA, 111, 3280-3285, 2013.

Garnaud, C., Sushama, L., and Verseghy, D.: Impact of interactive vegetation phenology on the Canadian RCM simulated climate over North America, Clim. Dynam., 45, 1471-1492, https://doi.org/10.1007/s00382-014-2397-9, 2015.

Gobron, N., Belward, A., and Knorr, W.: Monitoring biosphere vegetation 1998-2009, Geophys. Res. Lett., 37, L15402, https://doi.org/10.1029/2010GL043870, 2010.

Hurtt, G. C., Chini, L. P., Frolking, S., Betts, R. A., Feddema, J., Fischer, G., Fisk, J. P., Hibbard, K., Houghton, R. A., Janetos, A., Jones, C. D., Kindermann, G., Kinoshita, T., Klein Gold- ewijk, K., Riahi, K., Shevliakova, E., Smith, S., Stehfest, E., Thomson, A., Thornton, P., Van Vuuren, D. P., and Wang, Y. P.: Harmonization of land-use scenarios for the period 1500-2100: 600 years of global gridded annual land-use transitions, wood harvest, and resulting secondary lands, Climatic Change, 109, 117-161, 2011.

Kramer, P. J. and Kozlowski, T. T.: Physiology of Woody Plants, Academic Press, New York, San Francisco, London, 1979.

Koven, C. D., Riley, W. J., and Stern, A.: Analysis of permafrost thermal dynamics and response to climate change in the CMIP5 Earth System Models, J. Climate, 26, 1877-1900, 2013.

Lawley, E. F., Lewis, M. M., and Ostendorf, B.: Evaluating MODIS soil fractional cover for arid regions, using albedo from highspatial resolution satellite imagery, Int. J. Remote Sens., 35, 2028-2046, 2014

Le Quéré, C., Andrew, R. M., Canadell, J. G., Sitch, S., Korsbakken, J. I., Peters, G. P., Manning, A. C., Boden, T. A., Tans, P. P., Houghton, R. A., Keeling, R. F., Alin, S., Andrews, O. D., Anthoni, P., Barbero, L., Bopp, L., Chevallier, F., Chini, L. P., Ciais, P., Currie, K., Delire, C., Doney, S. C., Friedlingstein, P., Gkritzalis, T., Harris, I., Hauck, J., Haverd, V., Hoppema, M., Klein Goldewijk, K., Jain, A. K., Kato, E., Körtzinger, A., Landschützer, P., Lefèvre, N., Lenton, A., Lienert, S., Lombardozzi, D., Melton, J. R., Metzl, N., Millero, F., Monteiro, P. M. S., Munro, D. R., Nabel, J. E. M. S., Nakaoka, S.-I., O’Brien, K., Olsen, A., Omar, A. M., Ono, T., Pierrot, D., Poulter, B., Rödenbeck, C., Salisbury, J., Schuster, U., Schwinger, J., Séférian, R., Skjelvan, I., Stocker, B. D., Sutton, A. J., Takahashi, T., Tian, H., Tilbrook, B., van der Laan-Luijkx, I. T., van der Werf, G. R., Viovy, N., Walker, A. P., Wiltshire, A. J., and Zaehle, S.: Global Carbon Budget 2016, Earth Syst. Sci. Data, 8, 605-649, https://doi.org/10.5194/essd-8-605-2016, 2016.

Melton, J. R. and Arora, V. K.: Sub-grid scale representation of vegetation in global land surface schemes: implications for estimation of the terrestrial carbon sink, Biogeosciences, 11, 10211036, https://doi.org/10.5194/bg-11-1021-2014, 2014.

Melton, J. R. and Arora, V. K.: Competition between plant functional types in the Canadian Terrestrial Ecosystem Model (CTEM) v. 2.0, Geosci. Model Dev., 9, 323-361, https://doi.org/10.5194/gmd-9-323-2016, 2016.

Melton, J. R., Shrestha, R. K., and Arora, V. K.: The influence of soils on heterotrophic respiration exerts a strong control on net ecosystem productivity in seasonally dry Amazonian forests, Biogeosciences, 12, 1151-1168, https://doi.org/10.5194/bg-121151-2015, 2015.

Peng, Y., Arora, V. K., Kurz, W. A., Hember, R. A., Hawkins, B. J., Fyfe, J. C., and Werner, A. T.: Climate and atmospheric drivers of historical terrestrial carbon uptake in the province of British Columbia, Canada, Biogeosciences, 11, 635-649, https://doi.org/10.5194/bg-11-635-2014, 2014.

Pielke, R. A., Avissar, R., Raupach, M., Dolman, A. J., Zeng, X., and Denning, S.: Interactions between the atmosphere and terrestrial ecosystem: influence on weather and climate, Global Change Biol., 4, 461-475, 1998.

Ramankutty, N. and Foley, J. A.: Estimating historical changes in global land cover: croplands from 1700 to 1992, Global Biogeochem. Cy., 13, 997-1027, 1999.

Ran, L., Pleim, J., Gilliam, R., Binkowski, F. S., Hogrefe, C., and Band, L.: Improved meteorology from an updated 
WRF/CMAQ modeling system with MODIS vegetation and albedo, J. Geophys. Res.-Atmos., 121, 2393-2415, https://doi.org/10.1002/2015JD024406, 2016.

Ritchie, T. C. and Macdonald, G. M.: The patterns of post-glacial spread of White Spruce, J. Biogeogr., 13, 527-540, 1986.

Ruesch, A. and Holly, K.: New IPCC Tier-1 Global Biomass Carbon Map For the Year 2000, available at: http://cdiac.ess-dive.lbl. gov/ftp/global_carbon/ (last access: 5 July 2013), Carbon Dioxide Information Analysis Center http://cdiac.ornl.gov (last access: 5 July 2013), Oak Ridge National Laboratory, Oak Ridge, Tennessee, 2008.

Shrestha, R. K., Arora, V. K., and Melton, J. R.: The sensitivity of simulated competition between different plant functional types to sub-grid-scale representation of vegetation in a land surface model, J. Geophys. Res.-Biogeo., 121, 809-828, https://doi.org/10.1002/2015JG003234, 2016.

Siemann, E. and Rogers, W. E.: Changes in light and nitrogen availability under pioneer trees may indirectly facilitate tree invasion of grasslands, J. Ecol., 91, 923-931, 2003.

Sitch, S., Smith, B., Prentice, I. C., Arneth, A., Bondeau, A., Cramer, W., Kaplan, J. O., Lucht, W., Sykes, M. T., Thonicke, K., and Venevsky, S.: Evaluation of ecosystem dynamics, plant geography and terrestrial carbon cycling in the LPJ dynamic global vegetation model, Global Change Biol., 9, 161-185, 2003.

Ste-Marie, C., Paré, D., and Gagnon, D.: The contrasting effects of Aspen and Jack Pine on soil nutritional properties depend on parent material, Ecosystems, 10, 1299-1310, 2007.

Teufel, B., Sushama, L., Arora, V., and Verseghy, D.: Impact of dynamic vegetation phenology on the simulated pan-Arctic land surface state, Clim. Dynam., submitted, 2017.

Timmons, D., Buchholz, T., and Veeneman, C. H.: Forest biomass energy: assessing atmospheric carbon impacts by discounting future carbon flows, GCB Bioenergy, 8, 631-643, https://doi.org/10.1111/gcbb.12276, 2016.

Verseghy, D. L., Mcfarlane, N. A., and Lazare, M.: CLASS - a Canadian land surface scheme for GCMs. II. Vegetation model and coupled runs, Int. J. Climatol., 13, 347-370, 1993.
Viovy, N.: CRU-NCEP reanalysis data version 4, available at: https://vesg.ipsl.upmc.fr/thredds/catalog/store/p529viov/ cruncep/V4_1901_2012/catalog.html (last access: May 2015), 2012.

Wang, A., Price, D. T., and Arora, V. K.: Estimating changes in global vegetation cover (1850-2100) for use in climate models, Global Biogeochem. Cy., 20, GB3028, https://doi.org/10.1029/2005GB002514, 2006.

Wang, G., Sun, S., and Mei, R.: Vegetation dynamics contributes to the multi-decadal variability of precipitation in the Amazon region, Geophys. Res. Lett., 38, L19703, https://doi.org/10.1029/2011GL049017, 2011.

Wen, X., Tang, G., Wang, S., and Huang, J.: Comparison of global mean temperature series, Adv. Clim. Change Res., 2, 187-192, 2011.

Wu, Y., Verseghy, D. L., and Melton, J. R.: Integrating peatlands into the coupled Canadian Land Surface Scheme (CLASS) v3.6 and the Canadian Terrestrial Ecosystem Model (CTEM) v2.0, Geosci. Model Dev., 9, 2639-2663, https://doi.org/10.5194/gmd9-2639-2016, 2016.

Zhang, Z., Xue, Y., Macdonald, G., Cox, P. M., and Collatz, G. J.: Investigation of North America vegetation variablilityvariability under recent climate: a study using the SSiB4/TRIFFID biophysical/dynamic vegetation model, J. Geophys. Res.-Atmos., 120, 1300-1321, 2015.

Zhu, Z., Bi, J., Pan, Y., Ganguly, S., Anav, A., Xu, L., Samanta, A., Piao, S., Nemani, R. R., and Myneni, R. B.: Global data sets of vegetation leaf area index (LAI)3g and fraction of photosynthetically active radiation (FPAR)3g derived from global inventory modeling and mapping studies (GIMMS) normalized difference vegetation index (NDVI3g) for the period 1981 to 2011, Remote Sens., 5, 927-948, https://doi.org/10.3390/rs5020927, 2013.

Zobler, L.: A world soil file for global climate modelling, Tech. Rep. NASA TM-87802, NASA, Washington, D.C., 14-32, 1986. 